
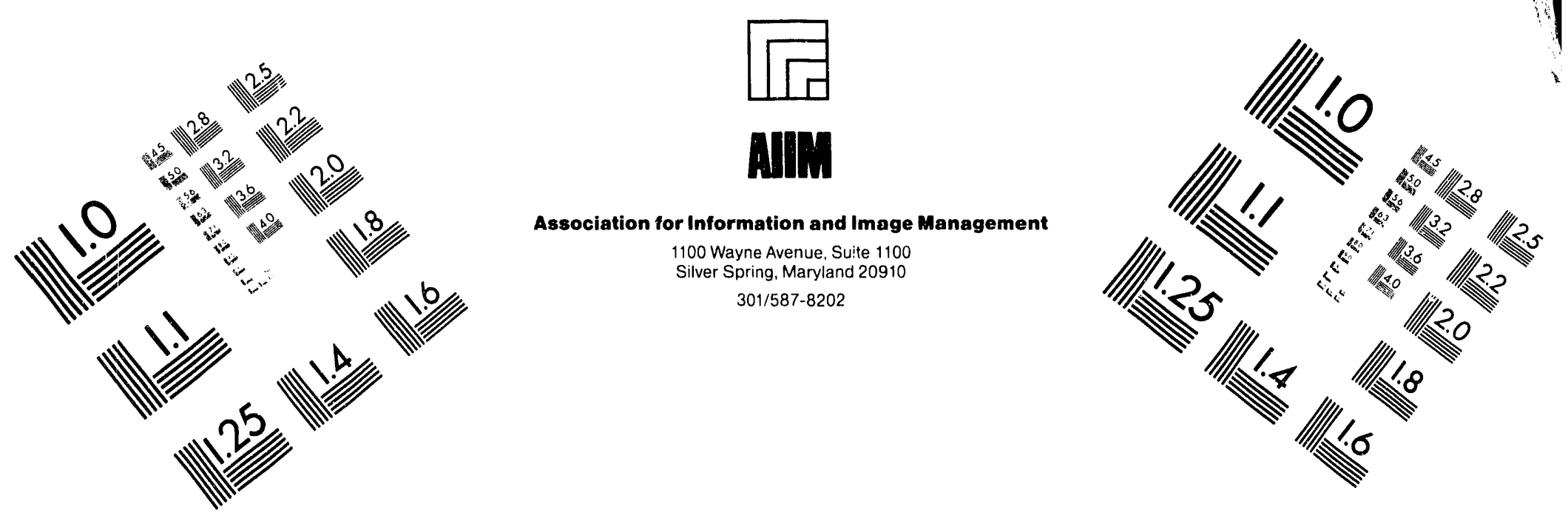

\title{
Centimeter
}

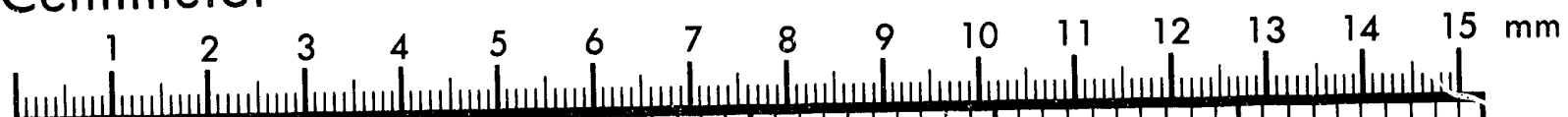

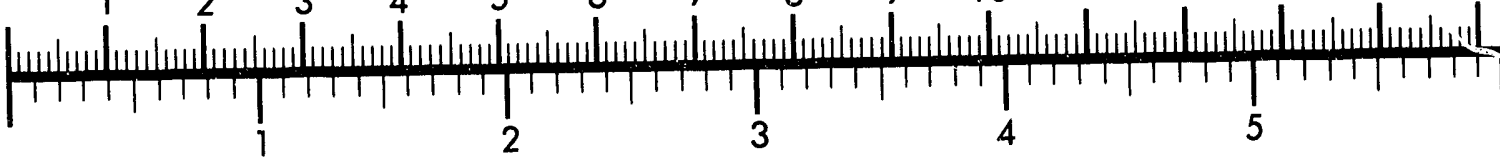
Inches
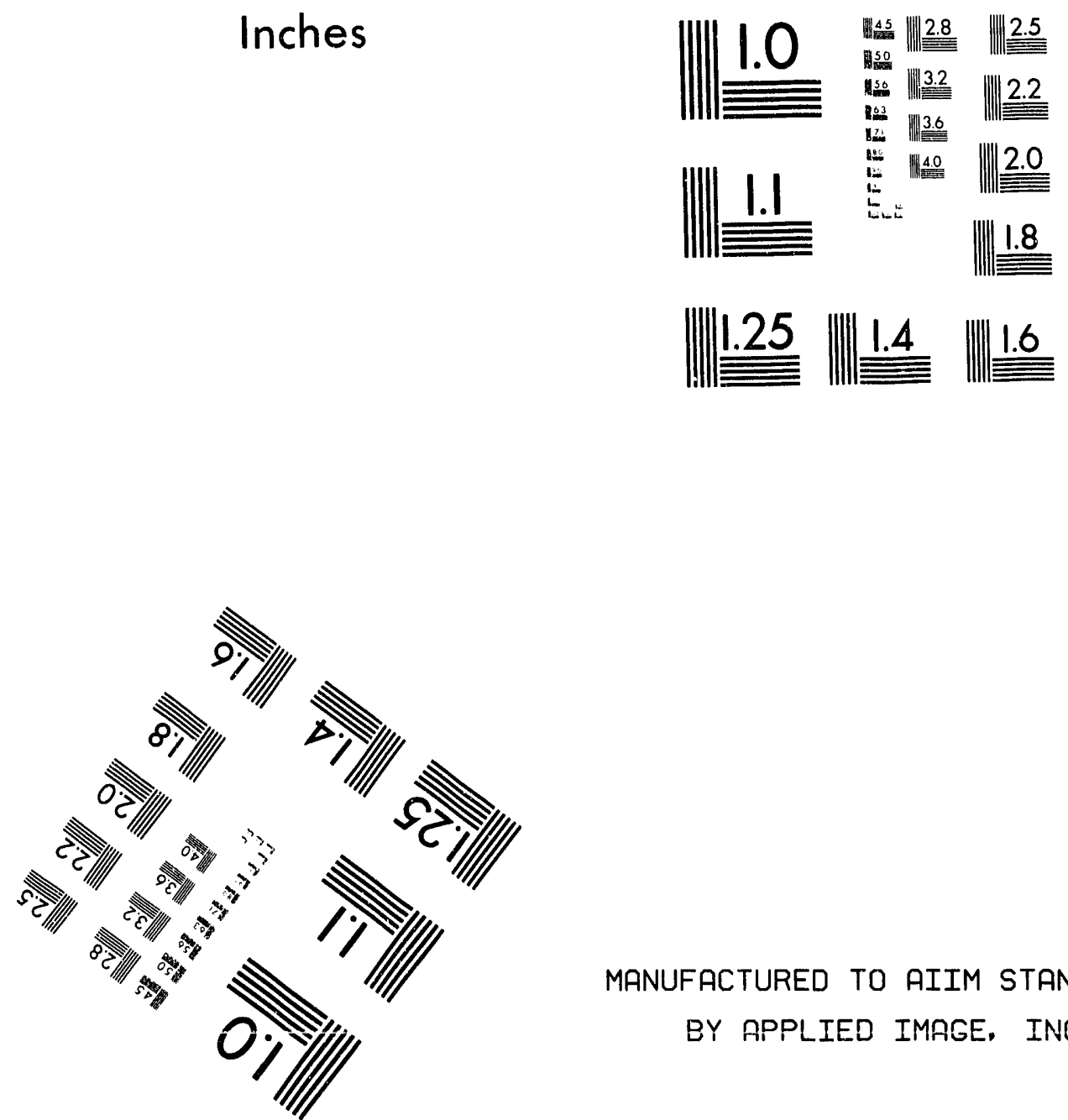

MANUFACTURED TO AIIM STANDARDS

BY APPLIED IMAGE, INC.

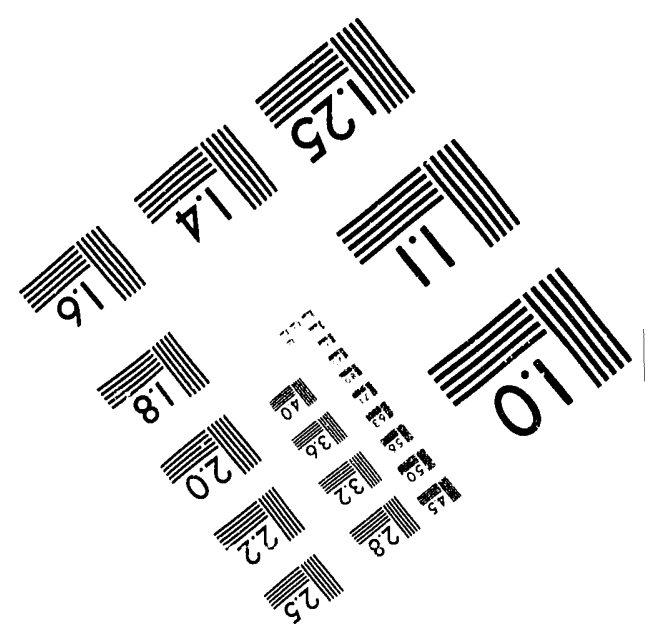



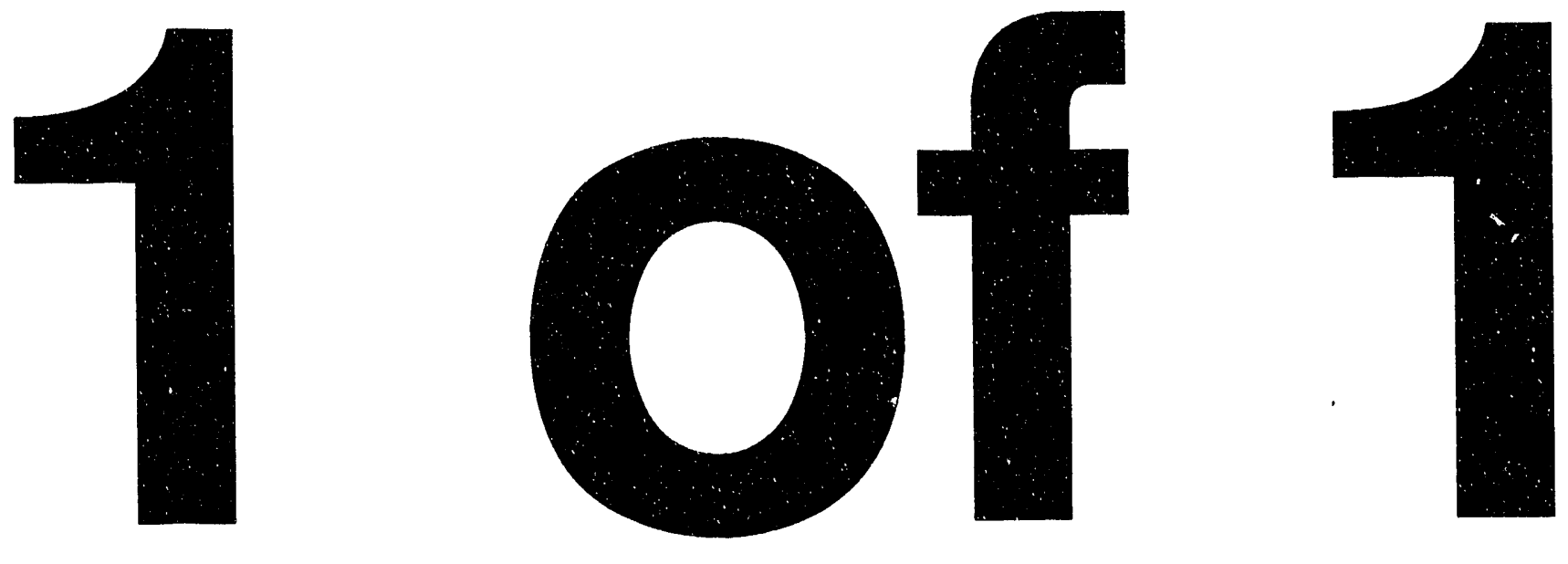


\title{
Argonne National Laboratory \\ 9700 South Cass Avenue \\ Argonne, Illinois 60439
}

\section{FREE VIBRATION ANALYSIS OF A TANK CONTAINING TWO LIQUIDS}

\author{
by
}

Yu Tang and Y. W. Chang

Reactor Engineering Division

May 1993
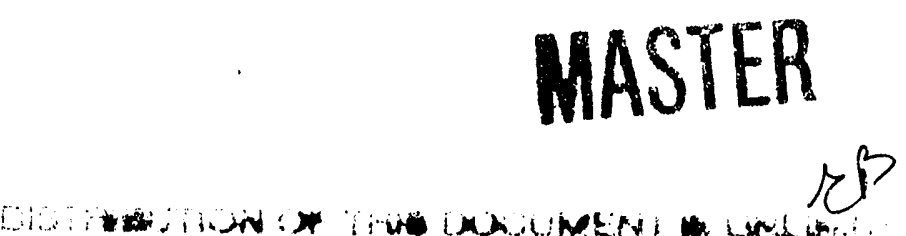


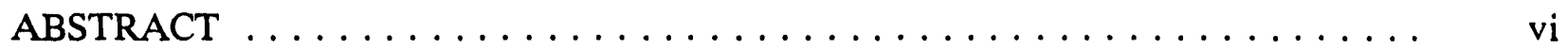

I. INTRODUCTION $\ldots \ldots \ldots \ldots \ldots \ldots \ldots \ldots \ldots \ldots \ldots \ldots \ldots \ldots \ldots \ldots$

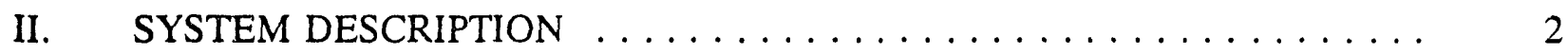

III. METHOD OF ANALYSIS $\ldots \ldots \ldots \ldots \ldots \ldots \ldots \ldots \ldots \ldots \ldots \ldots \ldots$

A. Kinetic Energy of Tank, $T_{s} \ldots \ldots \ldots \ldots \ldots \ldots \ldots \ldots$

B. Strain Energy of Tank, $S \ldots \ldots \ldots \ldots \ldots \ldots \ldots \ldots \ldots$

C. The Governing Equations and Boundary Conditions for Liquids .... 7

D. Kinetic Energy of Liquids, $T_{1} \ldots \ldots \ldots \ldots \ldots \ldots \ldots \ldots \ldots$

E. Eigenvalue Problem $\ldots \ldots \ldots \ldots \ldots \ldots \ldots \ldots \ldots \ldots \ldots$

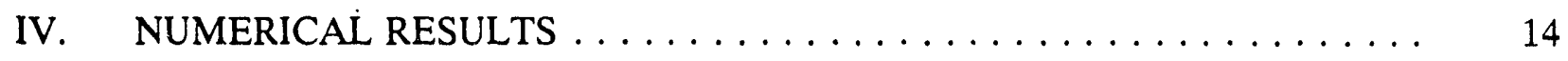

A. Fundamental Natural Frequency $\ldots \ldots \ldots \ldots \ldots \ldots \ldots \ldots \ldots$

B. Fundamental Mode of Vibration $\ldots \ldots \ldots \ldots \ldots \ldots \ldots \ldots \ldots$

C. Fundamental Mode of Hydrodynamic Pressure $\ldots \ldots \ldots \ldots \ldots \ldots$

V. SIMPLE EQUATION FOR EVALUATING FUNDAMENTAL NATURAL

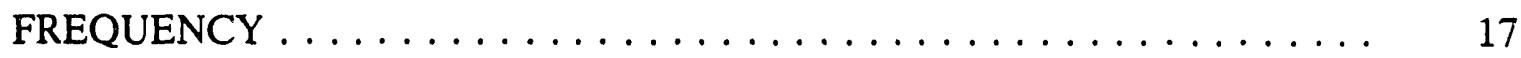

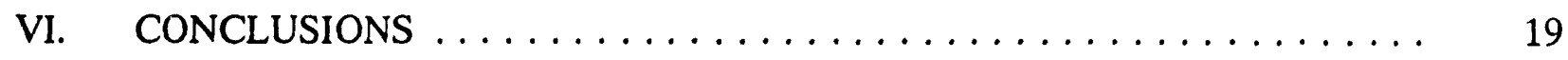

ACKNOWLEDGMENTS $\ldots \ldots \ldots \ldots \ldots \ldots \ldots \ldots \ldots \ldots \ldots \ldots \ldots \ldots \ldots$

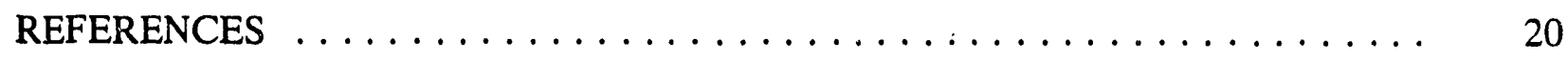




\section{LIST OF TABLES}

No.

$\underline{\text { Title }}$

Page

I Convergence Table of Frequency Coefficient $c_{1} \ldots \ldots \ldots \ldots \ldots$

22

II Comparison of Exact nd Approximate Fundamental Natural Frequency

for Steel Tank with $h / R=0.001, v=0.3$ and $\rho_{2} / \rho=0.127 \ldots \ldots \ldots \ldots$ 


\section{LIST OF FIGURES}

No.

Title

$\underline{\text { Page }}$

1 Tank-Two Liquid System Considered $\ldots \ldots \ldots \ldots \ldots \ldots$

2 Effect of Mass Densities on Fundamental Natural Frequency for Steel Tanks with $h / R=0.001, v=0.3$ and $\rho_{2} / \rho=0.127 \ldots \ldots \ldots$

3 Distributions of Axial Displacement of Fundamental Mode of Vibration for Steel Tanks with $h / R=0.001, v=0.3$ and $\rho_{2} / \rho=0.127 \ldots \ldots \ldots \ldots$

4 Distributions of Circumferential Displacement of Fundamental Mode of Vibration for Steel Tanks with $h / R=0.001, v=0.3$ and $p_{2^{\prime}} / \rho=0.1 \ldots \ldots$

5 Distributions of Radial Displacement of Fundamental Mode of Vibration for Steel Tanks with $h / R=0.001, v=0.3$ and $\rho_{2} / \rho=0.127 \ldots \ldots \ldots \ldots$

6 Distributions of Fundamental Model Hydrodynamic Pressure of Steel

Tank with $\mathrm{h} / \mathrm{R}=0.001, v=0.3$ and $\rho_{2} / \rho=0.127 \ldots \ldots \ldots$ 


\title{
FREE VIBRATION ANALYSIS OF A TANK CONTAINING TWO LIQUIDS
}

by

\author{
Yu Tang and Y. W. Chang
}

\begin{abstract}
A study of the dynamic characteristics of rigidly supported upright circular cylindrical tanks containing two different liquids is presented. The governing differential equations for the tank-two liquid system are obtained by application of the Rayleigh-Ritz procedure in combination with Lagrange's equation. The response functions examined include the fundamental natural frequency, the associated mode of vibration and hydrodynamic pressure exerted against the tank wall. Unlike the cases of tanks containing one liquid in which the dynamic response is controlled by four parameters, the dynamic response of a tank that contains two liquids is controlled by six parameters. The numerical results are presented in tabular and graphic forms, and are compared with those of the identical tank filled with one liquid. Also, a simple approximate equation for evaluating the fundamental natural frequency for preliminary design is proposed.
\end{abstract}




\section{INTRODUCTION}

The dynamic response of liquid-storage tanks subjected to earthquake ground motions has been a subject of numerous studies in the past thirty years. An excellent review of this topic can be found in Ref. 1. Most of the previous studies were focused on the tank containing only one liquid. However, there are cases in which the density of the tank content is not uniform. For example, in the paper by Burris, et al. [2], a new concept of reprocessing reactor spent fuel has been developed. This fuel recycling process is carried out primarily in a tank which contains two liquids with different densities. Also, a large number of high level waste storage tanks at various Department of Energy (DOE) facilities contain liquid with nonuniform density, see Ref. 3. For such cases, the adequacy of the design procedure based on the solutions obtained by assuming that tanks contain only one liquid becomes questionable. A study on the sloshing motion in a tank containing two liquids as reported in Refs. 4 and 5 shows that the sloshing wave height may be increased significantly as a result of the interaction of the two liquids. Therefore, it is necessary to understand how the two liquid interaction can affect the induced hydrodynamic pressure. In response to this need, a comprehensive study on the dynamic response of upright circular cylindrical liquid-storage tanks subjected to a horizontal ground motion has been studied by Tang $[6,7,8]$. However, in those papers only the rigid tank solutions were considered. Therefore, the effect of the tank wall flexibility on the response still needs to be answered. As the first step toward this goal, the dynamic characteristics of the tank filled with two liquids is studied, and the results are presented herein.

The objectives of this paper are: (1) to understand the effect of two-liquid interaction on the dynamic characteristics of the liquid storage tanks; (2) to present an analytical method of analysis for the computation of the natural frequencies of tanks containing two different liquids; and (3) to propose a simple approximate equation for the evaluation of the fundamental frequency of the tank-two liquid system.

The method of analysis presented herein is similar to that used in Ref. 9, and is basically the same as that used by Yang [10] and Tang [11], except that in the evaluation of the added mass of liquid, two liquids are involved in the present case. This approach is based on the Rayleigh-Ritz energy procedure in which the deflections of the tank wall are assumed to be linear combinations of the natural vibration modes of a uniform cantilever beam or the derivatives of 
those modes, and the liquid region is solved analytically. The governing differential equations of the tank-two fluid system are obtained by the application of Lagrange's equation.

Like the previous studies of Housner [12] and in Ref. 1, the hydrodynamic pressure is divided into two components: the impulsive component and the convective component. For the definitions of these two components, the reader is referred to Refs. 1 and 12. It has been pointed out in Ref. 1 and by Veletsos and Yang [13] and confirmed by Housner and Haroun [14] that the effect of the tank flexibility on the convective component is unimportant and can be neglected. Therefore, only the impulsive component is examined in this paper. Note that the convective component can be evaluated by considering the tank to be rigid.

\section{SYSTEM DESCRIPTION}

The tank-two liquid system investigated is shown in Fig. 1. It is a ground-supported upright circular cylindrical tank of radius $\mathrm{R}$ filled with two liquids to a total height of $\mathrm{H}$. The lower portion of liquid, identified as Liquid $I$, has a heavier mass density, $\rho_{1}$, and the upper portion of liquid, identify as Liquid II, has a lighter mass density; $\rho_{2}$. The height of Liquid $I$ and II are $\mathrm{H}_{1}$ and $\mathrm{H}_{2}$, respectively. Both liquids are considered to be incompressible and inviscid. The tank wall is assumed to be uniform thickness, h, and clamped to a rigid base. The mass density of the tank wall is denoted by $\rho$, and the modulus of elasticity and Poisson's ratio of the tank wall are denoted by $E$ and $\nu$, respectively. Points on the tank wall are specified by the cylindrical coordinate system, $r, \theta, z$. The origin of the coordinate system is taken at the center of the base. For convenience, two local cylindrical coordinates are used for the two liquids. Let $\mathrm{r}, \theta, \mathrm{z}_{1}$ denote the radial, sircumferential, and vertical axial coordinates of a point in the Liquid I, and let $r, \theta, z_{2}$ be the corresponding coordinates for a point in Liquid II as shown in Fig. 1. The coordinate $z$ is related to $z_{1}$ and $z_{2}$ by the equation

$$
z= \begin{cases}z_{1} & \text { for } 0 \leq z \leq H_{1} \\ z_{2}+H_{1} & \text { for } H_{1} \leq z \leq H\end{cases}
$$




\section{METHOD OF ANALYSIS}

The analysis is carried out by the application of the Rayleigh-Ritz method in combination with Lagrange's equation to obtain the governing differential equations.

The axial, tangential and radial components of the deflections of a point on the tank wall, $u, v$ and $w$ respectively, are expressed in terms of generalized coordinate functions $\chi_{i}(z)$ and $\psi_{i}(z)$, i.e.,

$$
\begin{aligned}
& u=\sum_{i=1}^{N 1} U_{i}(t) \chi_{i}(z) \cos \theta \\
& v=\sum_{i=1}^{N 2} V_{i}(t) \psi_{i}(z) \sin \theta \\
& w=\sum_{i=1}^{N 3} W_{i}(t) \Psi_{i}(z) \cos \theta
\end{aligned}
$$

where $\mathrm{U}_{\mathrm{i}}(\mathrm{t}), \mathrm{V}_{\mathrm{i}}(\mathrm{t})$ and $\mathrm{W}_{\mathrm{i}}(\mathrm{t})$ are time-dependent displacement amplitudes of the ith coordinate functions $\chi_{i}(z)$ and $\psi_{i}(z)$, and $N 1, N 2$ and $N 3$ are the number of coordinate functions used to approximate the displacements. A suitable choice of the generalized function $\psi_{i}(z)$ for a tank with free boundary conditions at top and fixed boundary condition at bottom would be the natural modes of vibration of a uniform cantilever beam. The second generalized coordinate function $\chi_{i}(z)$ is the first derivative of $\psi_{i}(z)$. These sets of generalized functions have been used previously in related studies $[9,10,11]$. Note that these generalized functions are geometrically admissible since they satisfy the boundary conditions at the tank base, i.e., $u=0, v=0, w=0$ and $\mathrm{dw} / \mathrm{dz}=0$.

The governing differential equations are obtained by the application of Lagrange's equation given as 


$$
\frac{d}{d t}\left(\frac{\partial\left(T_{s}+T_{l}\right)}{\partial \dot{q}_{i}}\right)-\frac{\partial\left(T_{s}+T_{l}\right)}{\partial q_{i}}+\frac{\partial S}{\partial q_{i}}=0
$$

for the ith equation in which $T_{s}$ is the kinetic energy of the tank and $T_{1}$ is the kinetic energy of the two liquids; $S$ is the strain energy of the tank wall, and $q_{i}$ is the generalized coordinates. In this study $q_{i}=U_{i}$ or $V_{i}$ or $W_{i}$. Obviously, if $T_{l}=0$, one would obtain the governing differential equations for the empty tank.

A. Kinetic Energy of Tank, $T_{\text {. }}$

The kinetic energy of the tank is given by

$$
T_{1}=\frac{\rho h}{2} \int_{0}^{2 \pi} \int_{0}^{H}\left(\dot{\mathrm{u}}^{2}+\dot{\mathrm{v}}^{2}+\dot{\mathrm{w}}^{2}\right) \mathrm{Rd} \mathrm{zd} \theta
$$

in which a dot superscript denotes the differentiation with respect to time.

\section{B. Strain Energy of Tank, $S$}

The strain energy of the tank is computed by making use the expression given in Bleich and Dimaggio [15]. It is 


$$
\begin{aligned}
S & =\frac{E}{2\left(1-v^{2}\right)} \frac{h}{R} \int_{0}^{2 \pi} \int_{0}^{H}\left[R^{2} u_{z}^{2}+\left(v_{\theta}+w\right)^{2}\right. \\
& \left.+2 v R u_{z}\left(v_{\theta}+w\right)+\frac{1-v}{2}\left(u_{\theta}+R v_{z}\right)^{2}\right] d z d \theta \\
& +\frac{E}{24\left(1-v^{2}\right)} \frac{h^{3}}{R^{3}} \int_{0}^{2 \pi} \int_{0}^{H}\left[R^{4} w_{z z}^{2}+\left(w_{\theta \theta}+w\right)^{2}\right. \\
& +\frac{1-v}{2}\left(R w_{z \theta}-u_{\theta}\right)^{2}+\frac{3(1-v)}{2} R^{2}\left(v_{z}+w_{z \theta}\right)^{2} \\
& \left.+2 v R^{2} w_{z z}\left(w_{\theta \theta}-v_{\theta}\right)-2 R^{3} u_{z} w_{z z}\right] \cdot d z d \theta
\end{aligned}
$$

in which the terms in the first bracket represent the extensional energy and the terms in the second bracket represent the bending energy. The subscripts $z$ and $\theta$ in the expression represent the derivatives of the quantity considered with respect to $z$ and $\theta$. Note that the expression presented in Eq. (5) differs a sign for $w$ from that given in Ref. 15. This is due to the different sign convention used for $w$ in this paper.

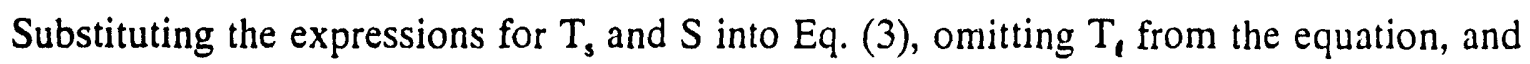
after repeating application of Eq. (3), one obtains a set of governing equations for the free vibration analysis of empty tanks. This work has been done by Yang [10] where the resultant equations are presented in a matrix form given by

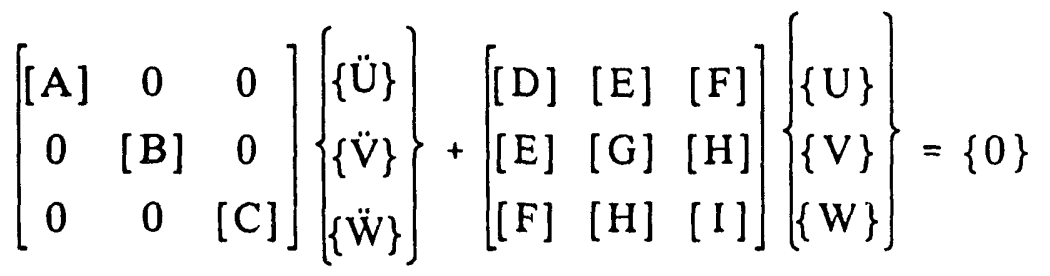


where $[A]$ through $[I]$ are square submatrices, and $\{U\},\{V\}$ and $\{W\}$ are the column submatrices whose elements are $U_{i}, i=1,2, \ldots, N 1 ; V_{i}, i=1,2, \ldots, N 2$; and $W_{i}, i=1,2, \ldots, N 3$, respectively. The elements of matrices [A] through [I] and the details of derivation of Eq. (6) can be found in Ref. 10. For the sake of presentation, Eq. (6) is written in a more compact form as

$$
[M]\{\ddot{q}\}+[K]\{q\}=\{0\}
$$

with the column matrix $\{\mathrm{q}\}$ defined by

$$
\begin{aligned}
&\{q\}=\left\{U_{1}(t), U_{2}(t), \ldots, U_{N 1}(t), V_{1}(t), V_{2}(t), \ldots, V_{N 2}(t),\right. \\
&\left.W_{1}(t), W_{2}(t), \ldots, W_{N 3}(t)\right\}^{\top}
\end{aligned}
$$

where the superscript $T$ denotes the transpose of the row matrix.

It has been shown by Yang [10] that the governing equations for a tank filled with liquid can be obtained by including the so-called liquid added mass to the mass matrix of the empty tank, and this liquid added mass is added to the elements associated with the radial displacement only; the presence of the liquid has no effect on the stiffness matrix, $[K]$. Specifically, if $c_{i j}$ denotes the element of the submatrix [C] in Eq. (6), $c_{i j}$ needs to be repla.ed by $c_{i j}{ }^{*}$ where $c_{i j}{ }^{*}$ is related to $c_{i j}$ by

$$
c_{i j}^{*}=c_{i j}+m_{i j}^{\prime}
$$

The quantity $m_{i j}^{l}$ in Eq. (9) is the so-called liquid added mass. The same procedure is employed herein to obtain the governing equations for tanks containing two liquids. The equation for computing the corresponding liquid added mass is presented as follows. 
C. The Governing Equations and Boundary Conditions for Liquids I and II

Given the conditions that the liquids are incompressible and inviscid, the velocity potentials for Liquids I and II, denoted by $\phi_{1}$ and $\phi_{2}$ respectively, must satisfy the Laplace equations

$$
\nabla^{2} \phi_{1}=0
$$

in the regicis $0 \leq r \leq R, 0 \leq \theta \leq 2 \pi$, and $0 \leq z_{1} \leq H_{1}$, and

$$
\nabla^{2} \phi_{2}=0
$$

in the region $0 \leq r \leq R, 0 \leq \theta \leq 2 \pi$, and $0 \leq z_{2} \leq H_{2}$.

The liquid velocity at an arbitrary point along $x$-direction, $v_{x}$, is given by

$$
v_{x}=-\frac{\partial \phi_{1}}{\partial x}
$$

for points in Liquid I, and

$$
v_{x}=-\frac{\partial \phi_{2}}{\partial x}
$$

for points in Liquid II. 
The boundary conditions for Liquid I are:

(a) The vertical velocity of Liquid I at the tank base must equal zero, i.e.,

$$
\left.\frac{\partial \phi_{1}}{\partial z_{1}}\right|_{z_{1}=0}=0
$$

(b) The radial velocity of Liquid I adjacent to the tank wall must equal the velocity of the tank wall, i.e.,

$$
-\left.\frac{\partial \phi_{1}}{\partial \mathrm{r}}\right|_{\mathrm{r}=\mathrm{R}}=\dot{\mathrm{W}}=\sum_{i=1}^{N 3} \dot{\mathrm{W}}_{\mathrm{i}}(\mathrm{t}) \psi_{\mathrm{i}}(\mathrm{z}) \cos \theta \text {, and }
$$

(c) The value of $\phi_{1}$ at $r=0$ is finite

The boundary conditions for Liquid II are:

(a) The radial velocity along the tank wall is given by

$$
-\left.\frac{\partial \phi_{2}}{\partial r}\right|_{r=R}=\dot{W}=\sum_{i=1}^{N 3} \dot{W}_{i}(t) \psi_{i}(z) \cos \theta \text {, and }
$$

(b) At the free surface, the pressure is equal to zero, i.e.,

$$
\left.\frac{\partial \phi_{2}}{\partial t}\right|_{z_{2}=H_{2}}=0, \text { and }
$$


(c) The value of $\phi_{2}$ at $r=0$ is finite.

The boundary conditions at the interface of two liquids are:

(a) Continuity of hydrodynamic pressure, i.e.,

$$
\left.\rho_{1} \frac{\partial \phi_{1}}{\partial t}\right|_{z_{1}=H_{1}}=\left.\rho_{2} \frac{\partial \phi_{2}}{\partial t}\right|_{z_{2}=0}
$$

and

(b) Continuity of vertical velocity, i.e.,

$$
\left.\frac{\partial \phi_{1}}{\partial z_{1}}\right|_{z_{1}=H_{1}}=\left.\frac{\partial \phi_{2}}{\partial z_{2}}\right|_{z_{2}=0}
$$

The method of separation of variables is used to solve the differential equations (10a) and (10b). The boundary conditions, Eqs. (13), (16), (17) and (18), are used to determine the eigenfunctions and eigenvalues, and the boundary conditions, Eqs (14) and (15), are used to determine the integration constants. The nth eigenfunction, denoted by $\Phi_{n}(z)$, is found to be

$$
\Phi_{n}(z)=\left\{\begin{array}{lc}
\alpha \cos \left(\lambda_{n} \frac{z_{1}}{H}\right) & 0 \leq z \leq H_{1} \\
\cos \beta_{1 n} \cos \left(\lambda_{n} \frac{z_{2}}{H}\right)-\alpha \sin \beta_{1 n} \sin \left(\lambda_{n} \frac{z_{2}}{H}\right) \quad H_{1} \leq z \leq H
\end{array}\right.
$$

where $\lambda_{n}$ is the $n$th eigenvalue which is the $n$th root of the characteristic equation given by 


$$
\cos \beta_{1 \mathrm{n}} \cos \beta_{2 \mathrm{n}}-\alpha \sin \beta_{1 \mathrm{n}} \sin \beta_{2 \mathrm{n}}=0
$$

Note that Eq. (20) has been presented in the paper by Tang [6] dealing with the hydrodynamic pressure in a rigid tank filled with two liquids. The notations used in Eqs (19) and (20) are explained as follows:

$$
\begin{aligned}
& \alpha=\frac{\rho_{2}}{\rho_{1}} \\
& \beta_{1 n}=\lambda_{n} \frac{H_{1}}{H}
\end{aligned}
$$

and

$$
\beta_{2 n}=\lambda_{n} \frac{H_{2}}{H}
$$

Introducing a notation $\phi(r, \theta, z)$ denoting the velocity potential at any point, $(r, \theta, z)$, in the liquid field, the solutions for the velocity potentials, $\phi_{1}$ and $\phi_{2}$, can be cast inio an expressed given by

$$
\begin{aligned}
\phi(r, \theta, z) & = \begin{cases}\phi_{1}\left(r, \theta, z_{1}\right) & \text { for } 0 \leq z \leq H_{1} \\
\phi_{2}\left(r, \theta, z_{2}\right) & \text { for } H_{1} \leq z \leq H_{2}\end{cases} \\
& =\left[\sum_{i=1}^{N} 3 \dot{W}_{i} F_{i}(r, z)\right] R \cos \theta
\end{aligned}
$$


Function $F_{i}(r, z)$ in Eq. (24) is given by

$$
F_{i}(r, z)=-\frac{H}{R} \sum_{n=1}^{\infty} \frac{2}{\lambda_{n}} \frac{I_{1}\left(\varepsilon_{n} \frac{r}{R}\right)}{I_{1}^{\prime}\left(\varepsilon_{n}\right)} \frac{d_{i n}}{\Delta_{n}} \Phi_{n}(z)
$$

in which $I_{1}$ is the modified Bessel function of the first kind and $I_{1}^{\prime}$ is its derivative, and

$$
\begin{aligned}
\varepsilon_{\mathrm{a}} & =\lambda_{\mathrm{n}} \frac{\mathrm{R}}{\mathrm{H}} \\
\mathrm{d}_{\mathrm{in}} & =\alpha \int_{0}^{\frac{H_{1}}{\mathrm{H}}} \psi_{\mathrm{i}}\left(\frac{\mathrm{z}}{\mathrm{H}}\right) \cos \left(\lambda_{\mathrm{n}} \frac{\mathrm{z}_{1}}{\mathrm{H}}\right) \mathrm{d}\left(\frac{\mathrm{z}_{1}}{\mathrm{H}}\right) \\
& +\cos \beta_{1 \mathrm{n}} \int_{0}^{\frac{\mathrm{H}_{2}}{\mathrm{H}}} \psi_{\mathrm{i}}\left(\frac{\mathrm{z}}{\mathrm{H}}\right) \cos \left(\lambda_{\mathrm{n}} \frac{\mathrm{z}_{2}}{\mathrm{H}}\right) \mathrm{d}\left(\frac{\mathrm{z}_{2}}{\mathrm{H}}\right) \\
& -\alpha \sin \beta_{1 \mathrm{n}} \int_{0}^{\frac{\mathrm{H}_{2}}{\mathrm{H}}} \psi_{\mathrm{i}}\left(\frac{\mathrm{z}}{\mathrm{H}}\right) \sin \left(\lambda_{\mathrm{n}} \frac{\mathrm{z}_{2}}{\mathrm{H}}\right) \mathrm{d}\left(\frac{\mathrm{z}_{2}}{\mathrm{H}}\right) \\
\Delta_{\mathrm{n}} & =\alpha \frac{\mathrm{H}_{1}}{\mathrm{H}}+\frac{\mathrm{H}_{2}}{\mathrm{H}}\left(\alpha^{2} \sin ^{2} \beta_{1 \mathrm{n}}+\cos ^{2} \beta_{1 \mathrm{n}}\right)
\end{aligned}
$$

Consequently, the corresponding hydrodynamic pressure, denoted by $p(r, \theta, z)$, can be obtained from the equation given by 


$$
p(r, \theta, z)= \begin{cases}\rho_{1} \frac{\partial \phi_{1}}{\partial t} & \text { for } 0 \leq z \leq H_{1} \\ \rho_{2} \frac{\partial \phi_{2}}{\partial t} & \text { for } H_{1} \leq z \leq H\end{cases}
$$

D. Kinetic Energy of Liquids. T,

For the incompressible and nonviscous fluids considered herein, it is shown by Currie [13] that the kinetic energy of the two liquids can be evaluated by the equation

$$
\mathrm{T}_{1}=\frac{\rho_{1}}{2} \iint_{\mathrm{s}_{1}} \phi_{1} \frac{\partial \phi_{1}}{\partial \mathrm{n}} \mathrm{ds} \mathrm{s}_{1}+\frac{\rho_{2}}{2} \iint_{\mathrm{s}_{2}} \phi_{2} \frac{\partial \phi_{2}}{\partial \mathrm{n}} \mathrm{ds} \mathrm{s}_{2}
$$

in which $\frac{\partial \phi_{1}}{\partial \mathrm{n}}$ and $\frac{\partial \phi_{2}}{\partial \mathrm{n}}$ are the derivatives of $\phi_{1}$ and $\phi_{2}$ in the direction normal to the boundaries of each liquid, respectively, and the symbols $s_{1}$ and $s_{2}$ are the surfaces which enclose Liquids I and II, respectively. The only non-zero part of the surface integral in Eq. (30) is the one associated with the tank wall; the value of $\frac{\partial \phi_{i}}{\partial n}, i=1,2$, in this case is equal to $\frac{\partial \phi_{i}}{\partial r}, i=1,2$, respectively. The integrals involving the tank bottom and free surface equal to zero are the results from the boundary conditions Eqs. (13) and (16), and the integrals at the interface of two liquids canceled each other are the result of the boundary conditions Eqs. (17) and (18). After eliminating those zero surface integrals, Eq. (30) can be rewritten as 


$$
\begin{aligned}
T_{1} & =\left.\frac{\rho_{1}}{2} \int_{0}^{2 \pi} \int_{0}^{H_{1}}\left[\phi_{1} \frac{\partial \phi_{1}}{\partial r}\right]\right|_{r=R} R d \theta d z_{1} \\
& +\left.\frac{\rho_{2}}{2} \int_{0}^{2 \pi} \int_{0}^{H_{2}}\left[\phi_{2} \frac{\partial \phi_{2}}{\partial r}\right]\right|_{r=R} R d \theta d z_{2}
\end{aligned}
$$

Substituting Eqs. (14), (15) and the resultant of Eq. (24) evaluated at $r=R$ into Eq. (31) and performing the indicated integration, one obtains

$$
T_{l}=\frac{1}{2} \sum_{i=1}^{N 3} \sum_{j=1}^{N 3} m_{i j}^{l} \dot{W}_{i} \dot{W}_{j}
$$

where

$$
m_{i j}^{\prime}=m_{12}\left[\frac{H}{R} \sum_{n=1}^{\infty} \frac{2}{\lambda_{n}} \frac{I_{1}\left(\varepsilon_{n}\right)}{I_{1}^{\prime}\left(\varepsilon_{n}\right)} \frac{d_{i n} d_{j n}}{\Delta_{n}}\right]
$$

in which $m_{12}=\pi H R^{2} \rho_{2}$, and $d_{j n}$ is obtained by replacing $\psi_{i}$ in Eq. (27) by $\psi_{j}$. The quantity $m_{i j}^{\prime}$ is the liquid added mass mentioned in Eq. (9).

\section{E. Eigenvalue Problem}

Replacing elements, $c_{i j}$ by $c_{i j}$ in the mass matrix, [M], and assuming that the time function of the vibration is a sinusoidal function, Eq. (7) leads to the standard form of an eigenvalue problem 
$[K]\{q\}=\omega^{2}[M]\{q\}$

where $\{q\}=$ the eigenvector which is the vector of the displacement amplitudes of vibration, and $\omega=$ the eigenvalue which is the natural circular frequency of the tank-two liquid system.

\section{NUMERICAL RESULTS}

Unlike the case of a tank containing one liquid where the response is controlled by four parameters, $H / R, h / R, \rho_{2} / \rho$ and $v$, the response of tanks containing two liquids is controlled by six parameters. These six parameters are $H / R, h / R, \rho_{2} / \rho, v, H_{2} / H_{1}$ and $\alpha$.

The numerical results presented in this paper are for steel tanks where $v$ is taken to be 0.3 . The lighter density liquid, Liquid II, is assumed to be water and the value for $\rho_{2} / \rho$ is taken to be 0.127 .

\section{A. Fundamental Natural Frequency}

The fundamental natural frequency of the tank-two liquid system may conveniently be expressed in the form of

$$
f=\frac{1}{2 \pi} \frac{c_{l}}{H} \sqrt{\frac{E}{\rho}}
$$

in which $\mathrm{f}$ has the unit of $\mathrm{Hz}$ (cycles per second), and $\mathrm{c}_{\mathrm{t}}$ is a nondimensional coefficient.

Values of $c_{\text {, }}$ for steel tanks with $H / R=0.5,1,2$ and 3 were obtained by using different combinations of N1, N2 and N3, and the results are listed in Table I. As expected, the value of $c_{1}$ decreases monotonously as the number of terms, N1, N2 and N3 increase. In Table I, the combination of $\mathrm{N} 1, \mathrm{~N} 2$ and $\mathrm{N} 3$ stops at $\mathrm{N} 1=9, \mathrm{~N} 2=9$ and $\mathrm{N} 3=9$. This is due to the limitation of the arithmetic precision imposed by the digital computer. In the computation of the integral defined in Eq. (27) for a tank containing two liquids, of the vibration modes of a uniform cantilever beam are evaluated at intermediate points and end points. It has been found that even 
with the double precision words of the digital computer (IBM 3270), these vibration modes can be calculated accurately only up to the ninth mode. To assess the accuracy of the numerical results obtained by taking $\mathrm{N} 1=9, \mathrm{~N} 2=9$ and $\mathrm{N} 3=9$, the data reported in Ref. 11 for the case of one liquid $(\alpha=1)$ are also listed in Table I for comparison. These data were obtained by taking $\mathrm{N} 1=10, \mathrm{~N} 2=15$ and $\mathrm{N} 3=20$. Note that for the case of $\alpha=1$, only the two end points of the vibration modes need to be calculated, and the exact values for these two end points are available in Ref. 17. From Table I one can see clearly that the difference of the two results is less than 1.5 percent, which is within engineering accuracy. Thus all solutions presented herein are obtained by using the combination of $\mathrm{N} 1=9, \mathrm{~N} 2=9$ and $\mathrm{N} 3=9$.

To study the effect of the liquid densities on the fundamental frequency, the values of $c_{1}$ are presented graphically in Fig. 2 for two different values of $\mathrm{H}_{2} / \mathrm{H}_{1}, 0.5$ and 2, as a function of $\alpha$. Four different values of $H / R$ are considered; they are $0.5,1,2$ and 3. From Fig. 2 it is noted that the value of $c_{1}$ decreases with decreasing value of $\alpha$, and the decrease is more rapid for small values than for large values of $\mathrm{H}_{2} / \mathrm{H}_{1}$. This indicates that due to the interaction of the two liquids the natural frequency of the tank-two liquid system may be quite different from that of the identical tank filled with one liquid. For example, for a steel tank with the value of $H / R$ equal to 1 , the value of $c_{1}$ is 0.0877 if the tank is filled with water; whereas the value of $c_{l}$ is 0.0757 if the tank is filled with two liquids with $\alpha=0.5$ and $\mathrm{H}_{2} / \mathrm{H}_{1}=1$, a difference of 15 percent is noted.

\section{B. Fundamental Mode of Vibration}

If $\{\hat{q}\}$ denotes the fundamental eigenvector obtained by solving the eigenvalue problem defined by Eq. (34), and the elements of $\{\hat{q}\}$ are denoted by $\hat{U}_{i}, i=1$ to $N 1, \hat{V}_{i}, i=1$ to $N 2$ and $\hat{\mathrm{W}}_{\mathrm{i}}, \mathrm{i}=1$ to $\mathrm{N} 3$, the distributions of the axial, circumferential, and radial displacements, denoted by $\hat{\mathrm{u}}(\mathrm{z}), \hat{\mathrm{v}}(\mathrm{z})$ and $\hat{\mathrm{w}}(\mathrm{z})$ respectively, can be computed from the equations

$$
\hat{u}(z)=\sum_{i=1}^{N 1} \hat{U}_{i} x_{i}(z)
$$




$$
\hat{v}(z)=\sum_{i=1}^{N 2} \hat{V}_{i} \psi_{i}(z)
$$

and

$$
\hat{w}(z)=\sum_{i=1}^{N 3} \hat{W}_{i} \psi_{i}(z)
$$

These equations are deduced from Eqs. (2a), (2b) and (2c).

The distribution functions, $\hat{\mathrm{u}}(\mathrm{z}), \hat{\mathrm{v}}(\mathrm{z})$ and $\hat{\mathrm{w}}(\mathrm{z})$, for $\alpha=0.5$ and $1, \mathrm{H}_{2} / \mathrm{H}_{1}=0.5$ and 2 are shown in Figs. 3, 4 and 5, respectively, for a broad tank, $H / R=0.5$ and a tall tank, $H / R=3$. These distributions are normalized with respect to the maximum value of the three functions. Note that from these figures the displacements $\hat{u}$ and $\hat{v}$ have an opposite sign to that of $\hat{w}$, i.e., when $\hat{w}$ is positive, both $\hat{u}$ and $\hat{v}$ are negative. One also notes that for the broad tank, the magnitudes of $\hat{u}$ and $\hat{v}$ are much less than that of $\hat{\mathbf{w}}$, while for the tall tank, $\hat{v}$ and $\hat{w}$ are comparable and $\hat{u}$ is still small. Generally speaking, the distributions of $\hat{u}, \hat{v}$ and $\hat{w}$ have the same shape for two values of $\alpha$ considered except for $\hat{w}$ in the case of the broad tank where a more clear change in the distribution is observed, see Fig. 5 (a) for $H / R=0.5$. Inspection of Figs. 3,4 and 5 also show that for tall tanks the mode shapes of $\hat{v}$ and $\hat{w}$ are very close to that of the cantilever beam, and the mode shape of $\hat{u}$ is close to that of the shear beam.

\section{Fundamental Mode of Hydrodynamic Pressure}

The fundamental mode of the hydrodynamic pressure exerted at the tank wall can be obtained by replacing $\dot{W}_{i}$ in Eq. (24) by $\hat{W}_{i}$, then, substituting the resultant equation into Eq. (29), and evaluating the resultant equation at $r=R$. As can be seen, the circumferential distribution of the pressure is proportional to $\cos \theta$ which is the same as that for the case of tanks filled with one liquid. 
The distributions of the fundamental mode of the hydrodynamic pressure exerted at the tank wall, denoted by $\hat{\mathrm{p}}(\mathrm{z})$, are presented in Fig. 6 for the same parameters considered in Figs. 3, 4 and 5. Note that unlike the displacement distributions sho'wn in Figs. 3, 4 and 5 where the effect of the parameter $\alpha$ is appreciable only in the radial displacement of the broad tank, the effect of $\alpha$ is noticeable for both the broad and tall tanks. It can be seen that with the presence of two liquids ( $\alpha=0.5$ ) the distribution has a slope change at the interface of the two liquids, and the center of gravity of the area enclosed by the curve for $\alpha=0.5$ is lower than that enclosed by the curve for $\alpha=1$. This indicates that the base moment arm is smaller for the tank filled with two liquids than that of an identical tank filled with only one liquid.

\section{SIMPLE EQUATION FOR EVALUATING FUNDAMENTAL NATURAL FREQUENCY}

The simple procedure for evaluating the impulsive response for a broad tank $(H / R \leq 1)$ containing only one liquid proposed by Veletsos and Yang [13] is very practical and useful for the preliminary design. It requires that the input ground acceleration, denoted by $\ddot{x}(t)$, in the rigid tank solutions be replaced by the pseudoacceleration function corresponding to the fundamental frequency of the tank-liquid system. It is believed that the proposed simple procedure can be extended for the preliminary design of the tanks containing two liquids. However, to implement that procedure for tanks containing two liquids, the fundamental frequency of the tank-two liquids system must be estimated. An equation for estimating the fundamental frequency of the tank-two liquid system is proposed herein. This equation is based on two assumptions: (1) the effective mass of the tank-two liquids system that participates in the first mode of vibration is equal to the impulsive component of the liquid added mass in the rigid tank, and (2) the mass of the tank wall itself is negligible in comparison to that of the liquid. The first assumption has been shown by Veletsos and Yang [13] to be a very good approximation for tanks filled with one liquid and with values of $H / R$ in the range between 0.25 and 1.0. The second assumption is a condition that normally can be justified in practice. Therefore, the equation proposed herein for estimating the fundamental frequency of the tank-two liquids system is also limited for tanks with values of $H / R$ in the range between 0.25 and 1.0. Note that this range is the practically important range. 
Conceptually, the original two liquids are replaced by an equivalent liquid, and the mass density of this equivalent liquid is cietermined by the criterion that the tank filled with the equivalent liquid yields the same base shear (considering only the impulsive component) as that in the same tank filled with the original two liquids on the assumption that the tank is rigid. Presented in a paper by Tang [7], the impulsive component of the base shear, denoted by $Q_{i}$ for rigid tanks containing two liquids can be expressed as

$$
\gamma_{i}=\gamma_{0} \rho_{1} \pi R^{2} H \ddot{x}(t)
$$

where $\%_{0}$ is a dimensionless coefficient depending on the vaiues of the parameters. $\mathrm{H} / \mathrm{R}, \mathrm{H}_{2} / \mathrm{H}_{1}$, and $\alpha$. If the ratio of two liquids is $\alpha_{0}$, then it is easy to show that the mass density of the equivalent liquid, denoted by $\rho^{\circ}$, is given by

$$
\rho^{*}=\frac{\left(\gamma_{0}\right)_{\alpha=\alpha_{0}}}{\left(\gamma_{0}\right)_{\alpha=1}} \rho_{1}
$$

After the mass density for the equivalent liquid is obtained, the fundamental frequency of the tank-two liquid system can be estimated from the data for the fundamental natural frequency of the tank filled with water using the equation given in Ref. 1. Specifically, if the fundamental natural frequency for tanks filled with water is expressed in the same form defined by Eq. (35), and the frequency coefficient $c_{1}$ for this case is denoted by $c_{w}$, then the frequency coefficient for a tank filled with two liquids with the value of $\alpha=\alpha_{0}$, denoted by $c^{\circ}$, can be computed from the equation

$$
c^{*}=c_{w} \sqrt{\frac{\rho_{w}}{\rho^{\bullet}}}
$$


where $\rho_{w}$ is the density of water. Extensive numerical data for the value of $c_{w}$ are available in Refs. 18,1 and 11 .

The frequency coefficient computed by Eq. (39) for three values of $\alpha, 0.25,0.5$ and 0.75 , two values of $\mathrm{H}_{2} / \mathrm{H}_{1}, 0.5$ and 2 , and values of $H / R$ in the range between 0.3 and 1 are listed in Table II. These data are referred to as approximate solutions, and also listed in Table II are the corresponding data, referred to as the exact solution, obtained by the analytical methods presented in the paper for the purpose of comparison. It can be seen that the proposed equation yields satisfactory results.

\section{CONCLUSIONS}

An analytical method of analysis for the study of the dynamic characteristics of tanks containing two liquids is presented. The method is based on the Rayleigh-Ritz procedure in combination with Lagrange's equation. The liquid region is solved analytically, and the displacements of the tank wall are expanded by the vibration modes of the cantilever beam. The method is easy to implement and may be expanded to include seismic excitations. The study presented herein shows that unlike the case of tanks containing one liquid in which the response is controlled by four parameters, the response of tanks containing two liquids is controlled by six parameters. Also, the dynamic characteristics of the system, the fundamental natural frequency, the associated mode of vibration and the hydrodynamic pressure, are affected by the interaction of the two liquids. Therefore, it is important to consider the presence of the two liquids in the design.

The fundamental frequency for tanks with values of $H / R$ between 0.25 and 1 can be estimated with good accuracy by the simple equation provided in this paper. This simple equation utilizes the rigid tank solution for a tank containing two liquids and the available data for tanks filled with water.

\section{ACKNOWLEDGMENT}

The authors wish to thank Mr. Ralph Seidensticker of Argonne National Laboratory for helpful discussions during the performance of this work. This work was performed in the 
Engineering Mechanics Program of the Reactor Engineering Division of Argonne National Laboratory under the auspices of the U.S. Department of Energy, Contract No. W-31-109-Eng-38.

\section{REFERENCES}

1. A. S. Veletsos, "Seismic Response and Design of Liquid Storage Tanks," Guidelines for the Seismic Design of Oil and Gas Pipeline Systems, Technical Council on Lifeline Earthquake Engineering, ASCE, pp. 255-370 and 443-461 (1984).

2. L. Burris, et al., "The Application of Electrorefining for Recovery and Purification of Fuel Discharged from the Integral Fast Reactor," AIChE Symposium Series, Vol. 83, No. 254, (1987).

3. Kamal K. Bandyopadhyay, "Overview of Seismic Panel Activities," Proc. Third DOE Natural Phenomena Hazards Mitigation Conf., St. Louis, Missouri, pp. 423-429 (1991).

4. Y. Tang, D. Ma, and Y. Chang, "Sloshing Response in a Tank Containing Two Liquids," Proc. of the 1991 ASME PVP Conf., Vol. 223, pp. 97-100 (1991).

5. Y. Tang, "Sloshing Displacements in a Tank Containing Two Liquids," to appear in Proc. of the 1993 ASME PVP Conference (1993).

6. Y. Tang, "Hydrodynamic Pressure in a Tank Containing Two Liquids," Proc. of the 1992 ASME PVP Conference, Vol. 223, pp. 97-104 (1992).

7. Y. Tang, "Dynamic Response of a Tank Containing Two Liquids," J. Engrg. Mechanics, ASCE, Vol. 119, No. 3, pp. 531-548 (1993).

8. Y. Tang and Y. W. Chang, "The Exact Solution to The Dynamic Response of Tanks Containing Two Liquids," ANL/RE-93/2 (1993).

9. A. S. Arya, S. K. Thakkar, and A. C. Goyal, "Vibration Analysis of Thin Cylindrical Containers," J. Engrg. Mechanics, ASCE, Vol. 97, No. 2, pp. 317-331 (1971).

10. J. Y. Yang, "Dynamic Behavior of Fluid-Tank Systems," Thesis presented to Rice University, Houston, TX, in partial fulfillment of the requirements for the degree of Doctor of Philosophy (1976).

11. Y. Tang, "Studies of Dynamic Response of Liquid Storage Tanks," Thesis presented to Rice University, Houston, TX, in partial fulfillment of the requirements for the degree of Doctor of Philosophy (1986). 
12. G. W. Housner, "Dynamic Pressure on Accelerated Fluid Container," Bull. Seismological Soc of America, Vol. 47, pp. 15-35 (1957).

13. A. S. Veletsos and J. Y. Yang, "Earthq'ake Response of Liquid Storage Tanks," Advances in Civil Engineering Through Engineering Mechanics, Proc. Engineering Mechanics Division Specialty Conference, ASCE, Rayleigh, NC, pp. 1-24 (1977).

14. M. A. Haroun and G. W. Housne:, "Complications in Free Vibration Analysis of Tanks," J. Engrg. Mechanics, ASCE, Vol. 108, No. 5, pp. 801-818 (1982).

15. H. H. Bleigh and F. Dimaggio, "A. Strain-Energy Expression for Thin Cylindrical Shelis," J. of Applied Mechanics, ASME, Vol. 75, pp. 448-449 (1953).

16. I. G. Currie, Fundamental Mechanics of Fluids, McGraw-Hill Book Company, New York, NY (1974).

17. R. P. Felgar, "Formulas for Integrals Containing Characteristic Functions of a Vibrating Beam," Texas University, Bureau of Engineering Research, Circular No. 14 (1950).

18. M. A. Haroun ard G. W, Housner, "Seismic Design of Liquid Storage Tanks," J. Tech. Councils of ASCE, Vol. 107, No. TC1, pp. 191-207 (1981). 
Table I. Convergence Table of Frequency Coefficient, $c_{\ell}$ (steel tanks with $h / R=0.001, v=0.3, \rho_{2} / \rho=0.127$ )

\begin{tabular}{|c|c|c|c|c|}
\hline \multirow[t]{2}{*}{$\begin{array}{c}\text { No. of } \\
\text { Terms } \\
\text { N1-N2-N3 }\end{array}$} & \multicolumn{4}{|c|}{ Frequency Coefficient, $c_{1}$} \\
\hline & $H / R=0.5$ & $H / R=1$ & $\mathrm{H} / \mathrm{R}=2$ & $\mathrm{H} / \mathrm{R}=3$ \\
\hline & & $\alpha=0.5$ & $\mathrm{H}_{2} / \mathrm{H}_{1}=1$ & \\
\hline $1-1-1$ & 0.111 & 0.131 & 0.199 & 0.0967 \\
\hline $3-3-3$ & 0.0670 & 0.0820 & 0.0843 & 0.0756 \\
\hline $3-3-5$ & 0.0639 & 0.0795 & 0.0835 & 0.0736 \\
\hline $5-5-9$ & 0.0619 & 0.0765 & 0.0809 & 0.0733 \\
\hline $7-7-9$ & 0.0617 & 0.0760 & 0.0801 & 0.0727 \\
\hline \multirow[t]{2}{*}{$9-9-9$} & 0.0617 & 0.0757 & 0.0796 & 0.0724 \\
\hline & & $\alpha=1$ & $\mathrm{H}_{2} / \mathrm{H}_{1}=1$ & \\
\hline $1-1-1$ & 0.116 & 0.139 & 0.127 & 0.102 \\
\hline $3-3-3$ & 0.0769 & 0.0943 & 0.0948 & 0.0828 \\
\hline $3-3-5$ & 0.0744 & 0.0923 & 0.0942 & 0.0824 \\
\hline $5-5-9$ & 0.0726 & 0.0896 & 0.0917 & 0.0807 \\
\hline $7-7-9$ & 0.0724 & 0.0890 & 0.0910 & 0.0801 \\
\hline 9-9-9 & 0.0723 & 0.0887 & 0.0906 & 0.0799 \\
\hline $10-15-20^{*}$ & 0.0719 & 0.0875 & 0.0896 & 0.0792 \\
\hline
\end{tabular}

${ }^{*}$ Taken from Ref. 8. 
Table II. Comparison of Exact and Approximate Fundamental Natural Frequency for Steel Tank with $h / R=0.001, v=0.3$ and $\rho_{2} / \rho=0.127$

\begin{tabular}{|c|c|c|c|c|c|c|}
\hline & \multicolumn{6}{|c|}{ Frequency Coefficient, $c^{*}$} \\
\hline & & & & & & \\
\hline \multirow[t]{2}{*}{$\mathrm{H} / \mathrm{R}$} & Exact & Approx. & Exact & Approx. & Exact & Approx. \\
\hline & \multicolumn{6}{|c|}{$\mathrm{H}_{2} / \mathrm{H}_{1}=0.5$} \\
\hline 0.3 & 0.0369 & 0.0387 & 0.0482 & 0.0492 & 0.0552 & 0.0555 \\
\hline 0.4 & 0.0408 & 0.0430 & 0.0535 & 0.0545 & 0.0613 & 0.0616 \\
\hline 0.5 & 0.0442 & 0.0462 & 0.0578 & 0.0586 & 0.0663 & 0.0663 \\
\hline 0.6 & 0.0471 & 0.0488 & 0.0615 & 0.0620 & 0.0704 & 0.0702 \\
\hline 0.7 & 0.0495 & 0.0507 & 0.0646 & 0.0646 & 0.0739 & 0.0734 \\
\hline 0.8 & 0.0516 & 0.0522 & 0.0672 & 0.0667 & 0.0768 & 0.0759 \\
\hline 0.9 & 0.0535 & 0.0533 & 0.0694 & 0.0684 & 0.0793 & 0.0780 \\
\hline \multirow[t]{2}{*}{1.0} & 0.0550 & 0.0542 & 0.0712 & 0.0697 & 0.0812 & 0.0798 \\
\hline & \multicolumn{6}{|c|}{$\mathrm{H}_{2} / \mathrm{H}_{1}=2$} \\
\hline 0.3 & 0.0490 & 0.0498 & 0.0552 & 0.0552 & 0.0581 & 0.0580 \\
\hline 0.4 & 0.0537 & 0.0553 & 0.0610 & 0.0612 & 0.0645 & 0.0644 \\
\hline 0.5 & 0.0579 & 0.0594 & 0.0659 & 0.0658 & 0.0696 & 0.0693 \\
\hline 0.6 & 0.0616 & 0.0628 & 0.0699 & 0.0696 & 0.0740 & 0.0734 \\
\hline 0.7 & 0.0649 & 0.0652 & 0.0734 & 0.0725 & 0.0776 & 0.0767 \\
\hline 0.8 & 0.0677 & 0.0672 & 0.0763 & 0.0749 & 0.0807 & 0.0794 \\
\hline 0.9 & 0.0700 & 0.0686 & 0.0787 & 0.0768 & 0.0832 & 0.0817 \\
\hline 1.0 & 0.0721 & 0.0697 & 0.0806 & 0.0783 & 0.0852 & 0.0835 \\
\hline
\end{tabular}




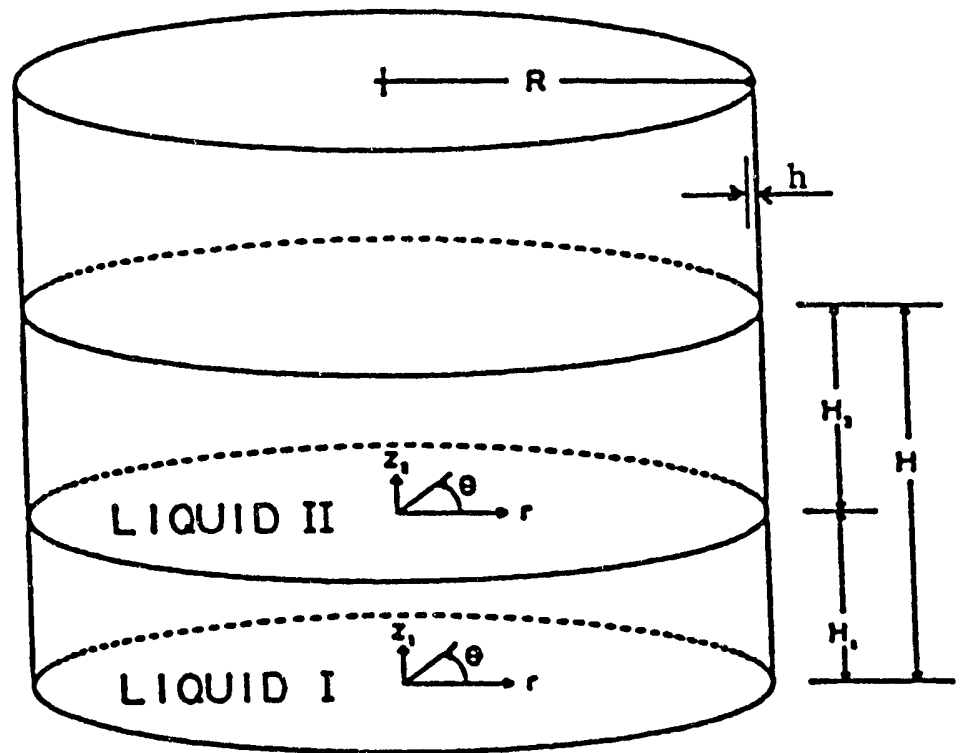

Fig. 1. Tank-Two Liquid System Considered 

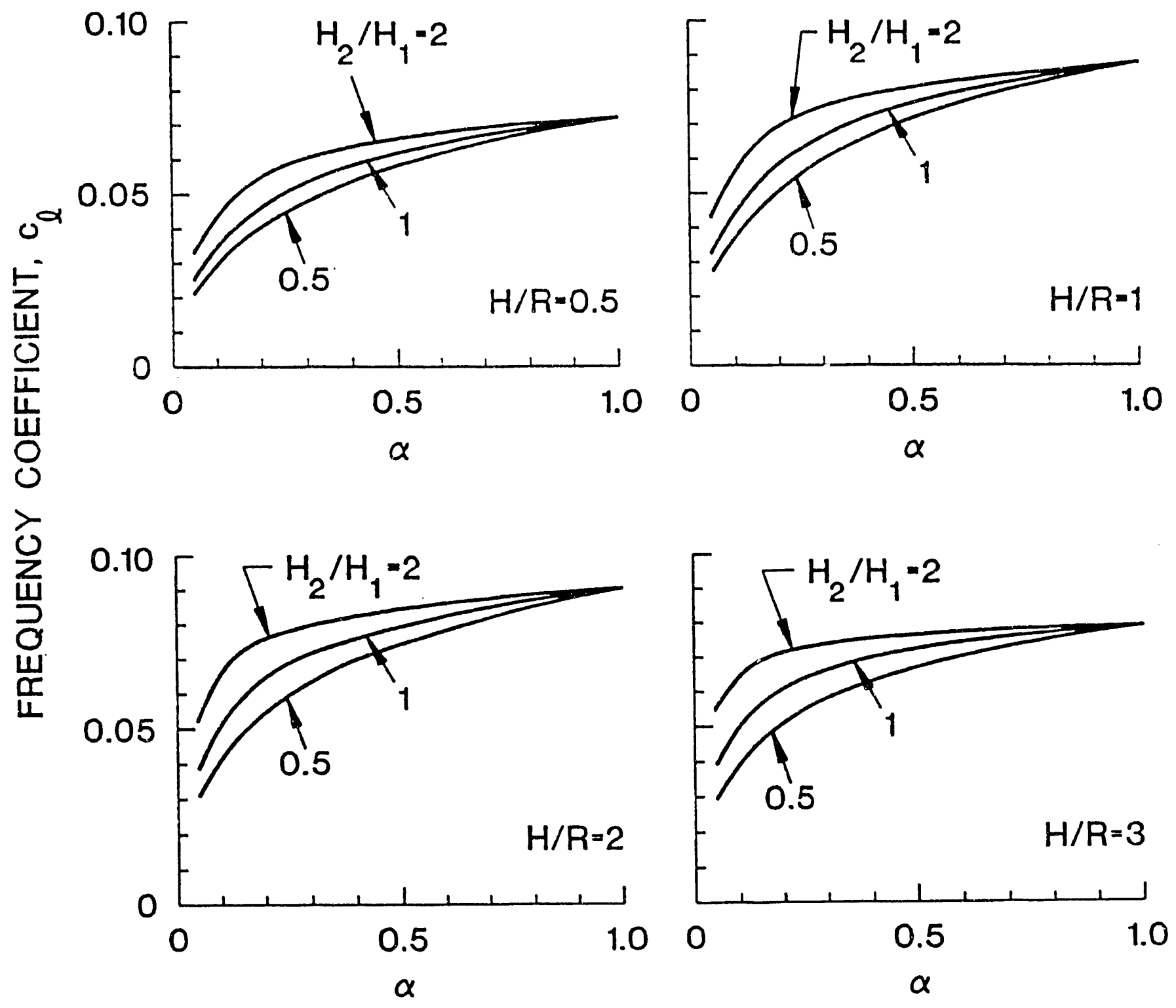

Fig. 2. Effect of Mass Densities on Fundamental Natural Frequency for Steel Tanks with $h / R=0.001, v=0.3$ and $\rho_{2} / \rho=0.127$ 

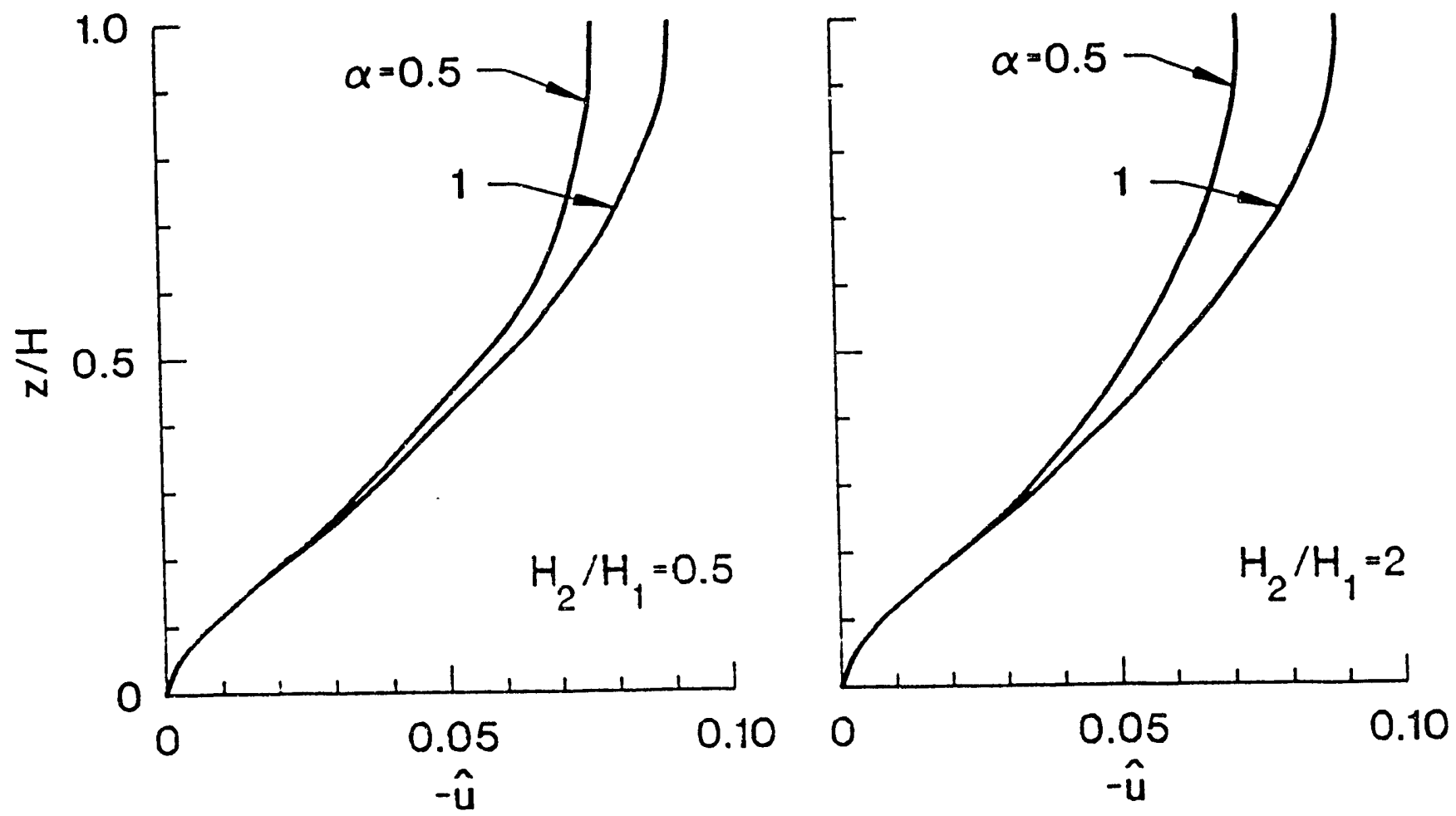

(a) $\mathrm{H} / \mathrm{R}=0.5$
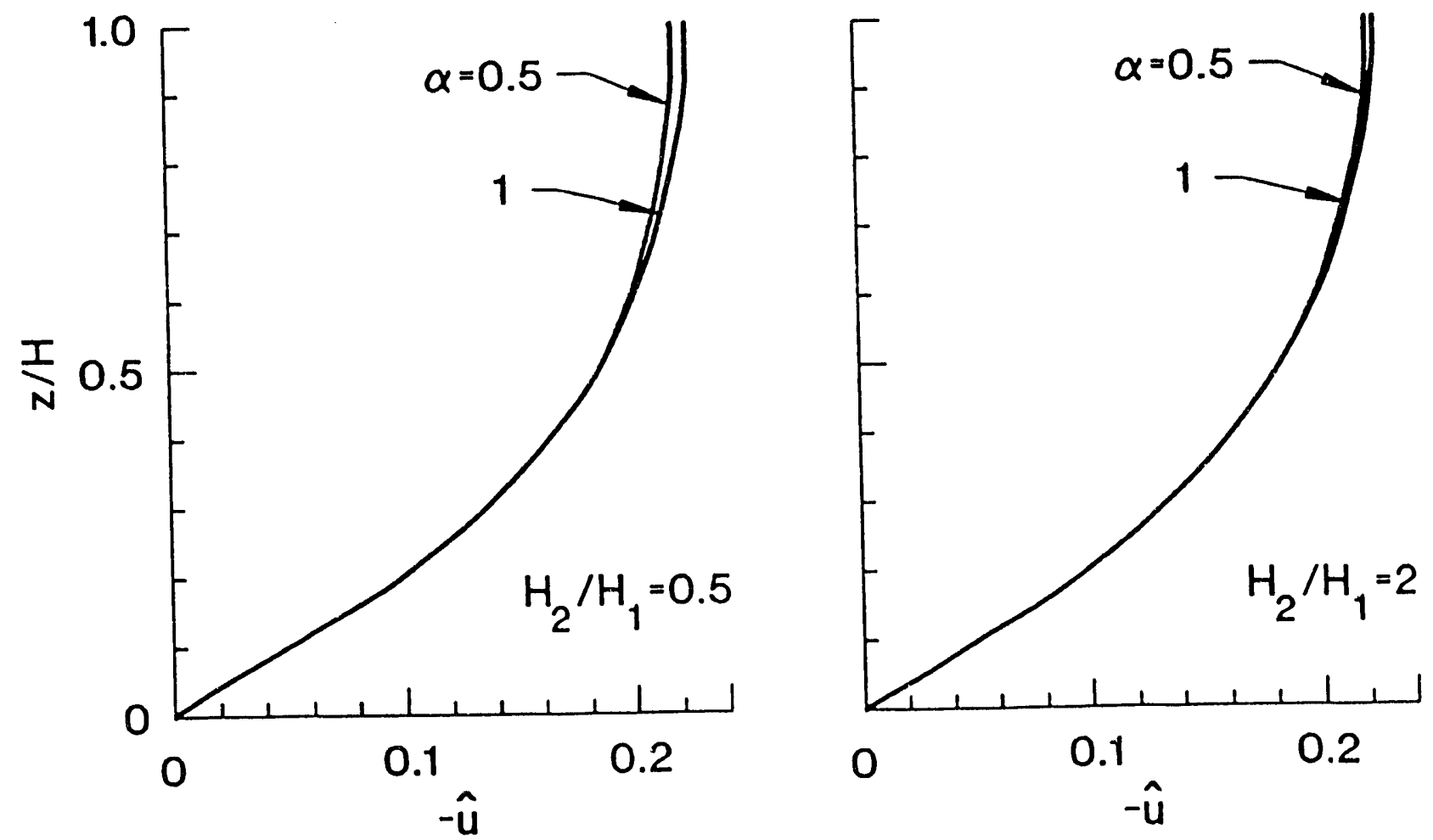

(b) $H / R=3$

Fig. 3. Distributions of Axial Displacement of Fundamental Mode of Vibration for Steel Tanks with $h / R=0.001, \nu=0.3$ and $\rho_{2} / \rho=0.127$ 

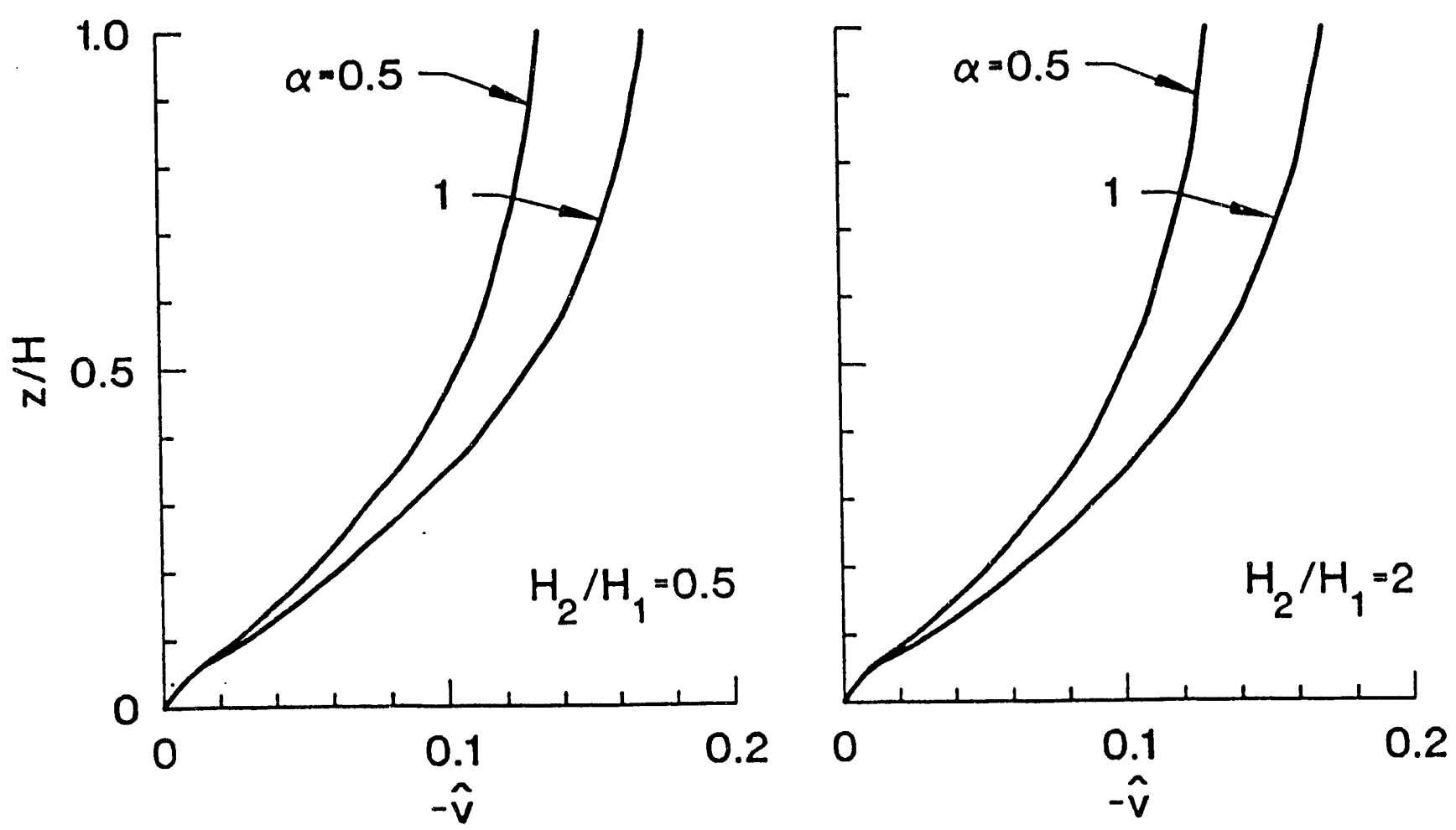

(a) $\mathrm{H} / \mathrm{R}=0.5$
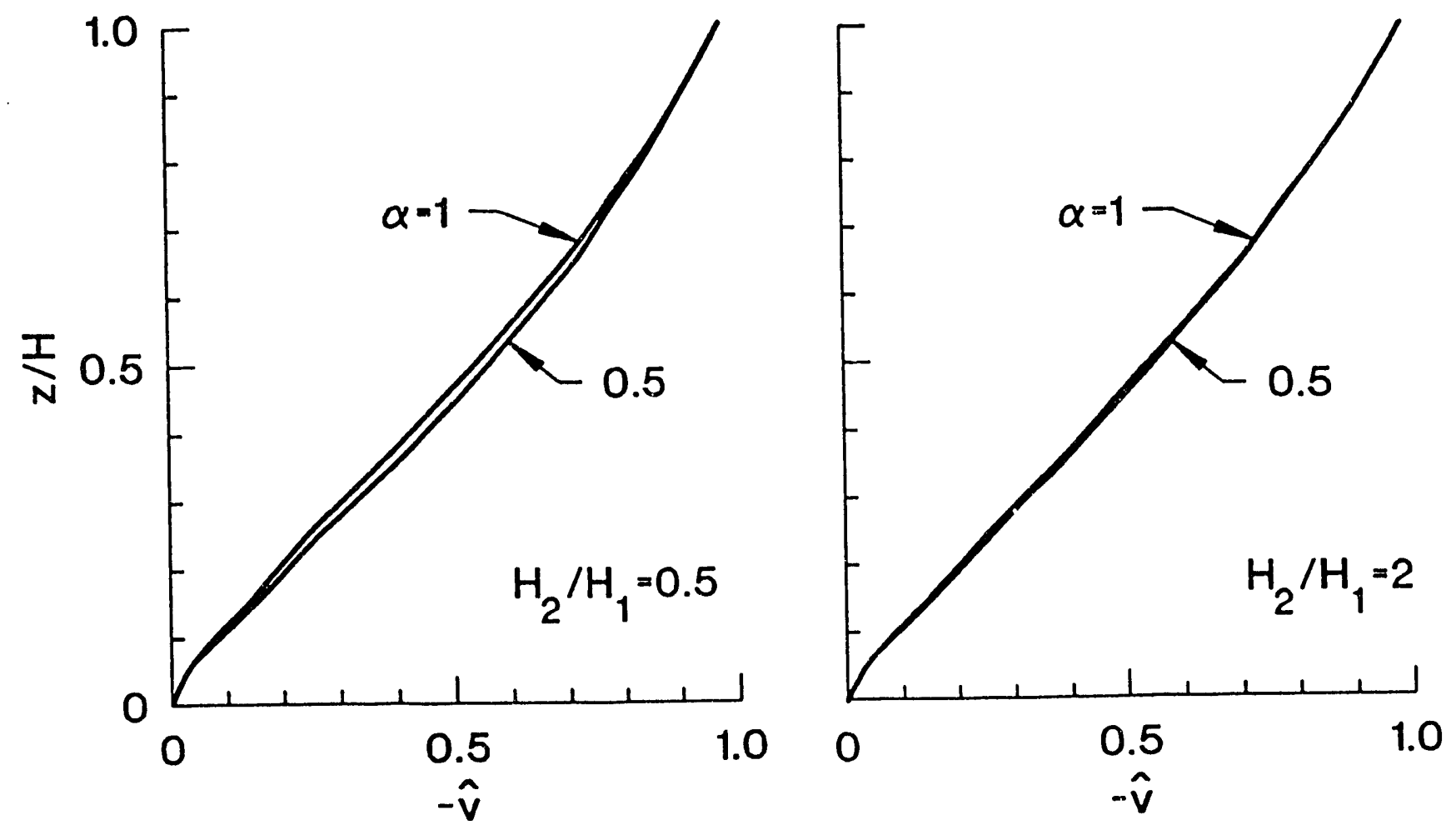

(b) $H / R=3$

Fig. 4. Distributions of Circumferential Displacement of Fundamental Mode of Vibration for Steel Tanks with $h / R=0.001, v=0.3$ and $\rho_{2} / \rho=0.1$ 

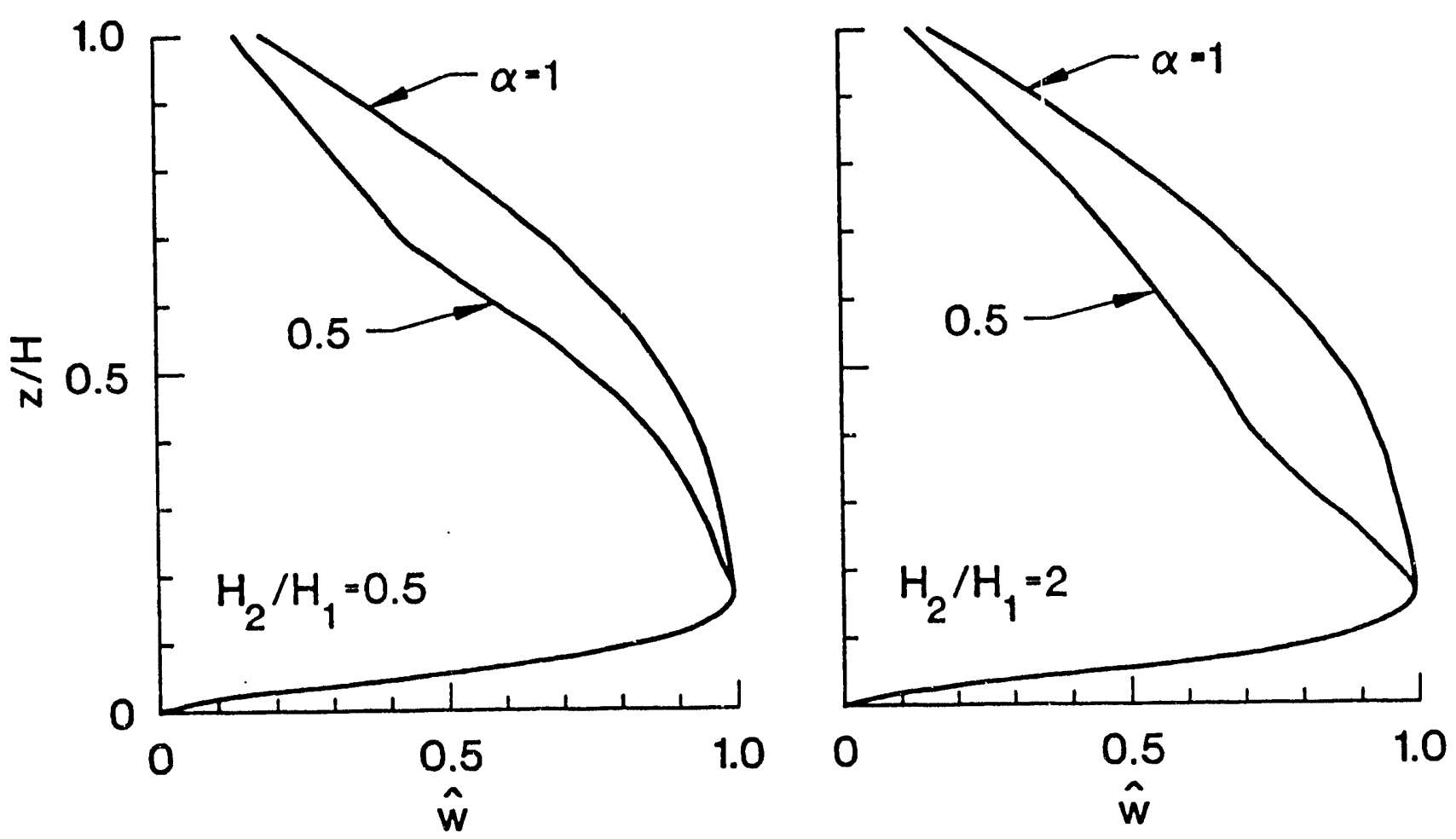

(a) $H / R=0.5$
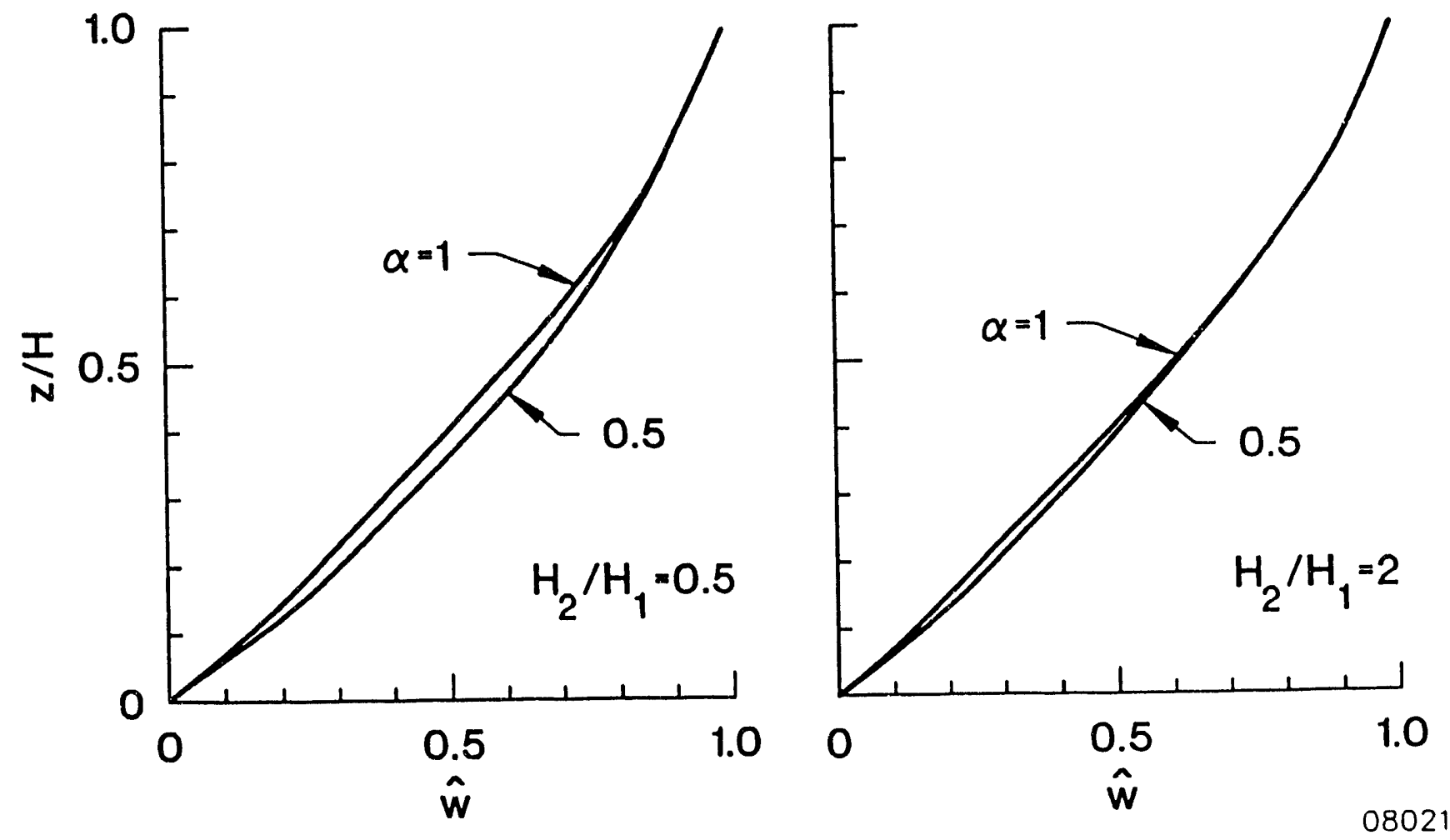

(b) $H / R=3$

Fig. 5. Distributions of Radial Displacement of Fundamental Mode of Vibration for Steel Tanks with $h / R=0.001, \nu=0,3$ and $\rho_{2} / \rho=0,127$ 

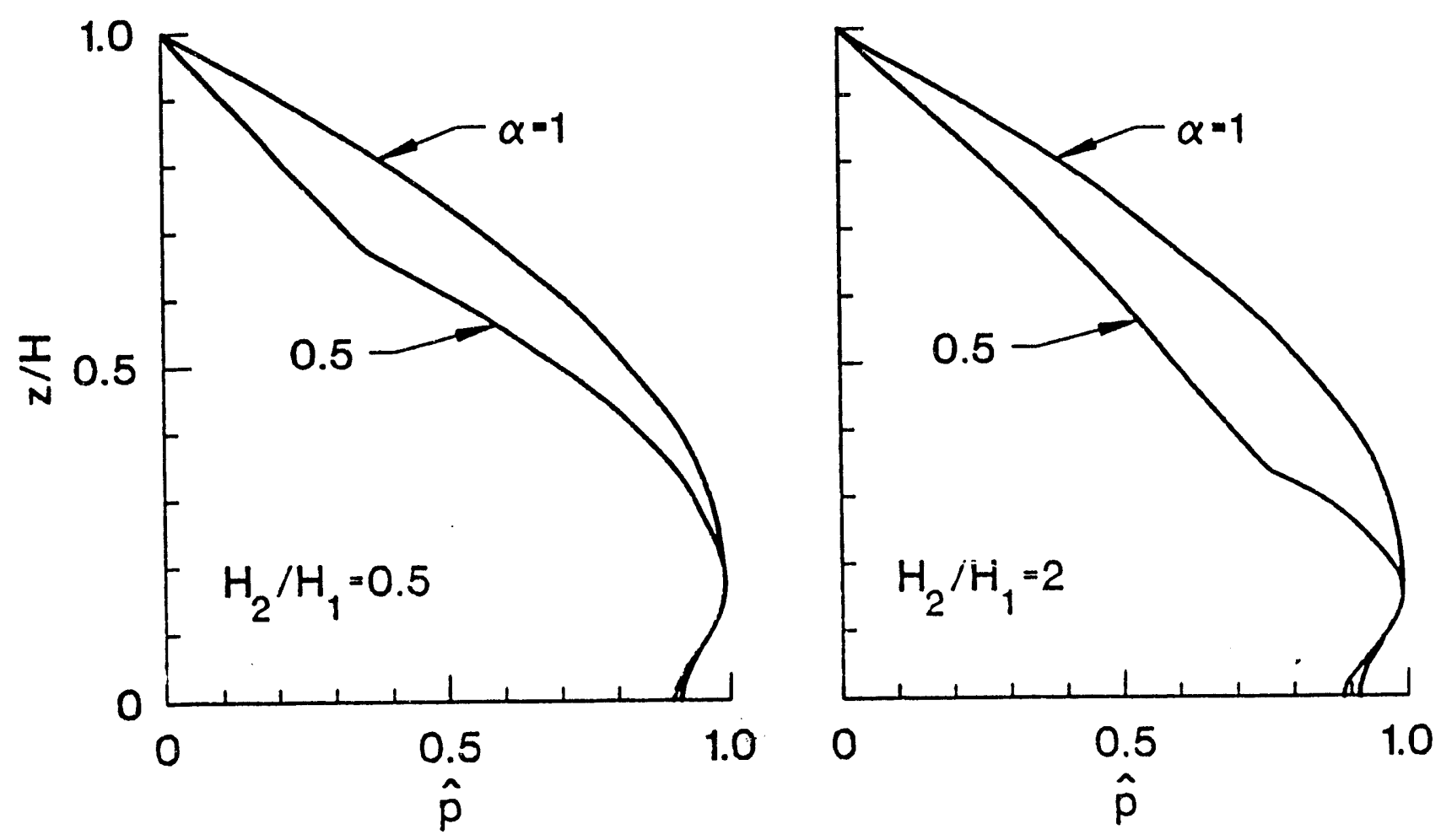

(a) $H / R=0.5$
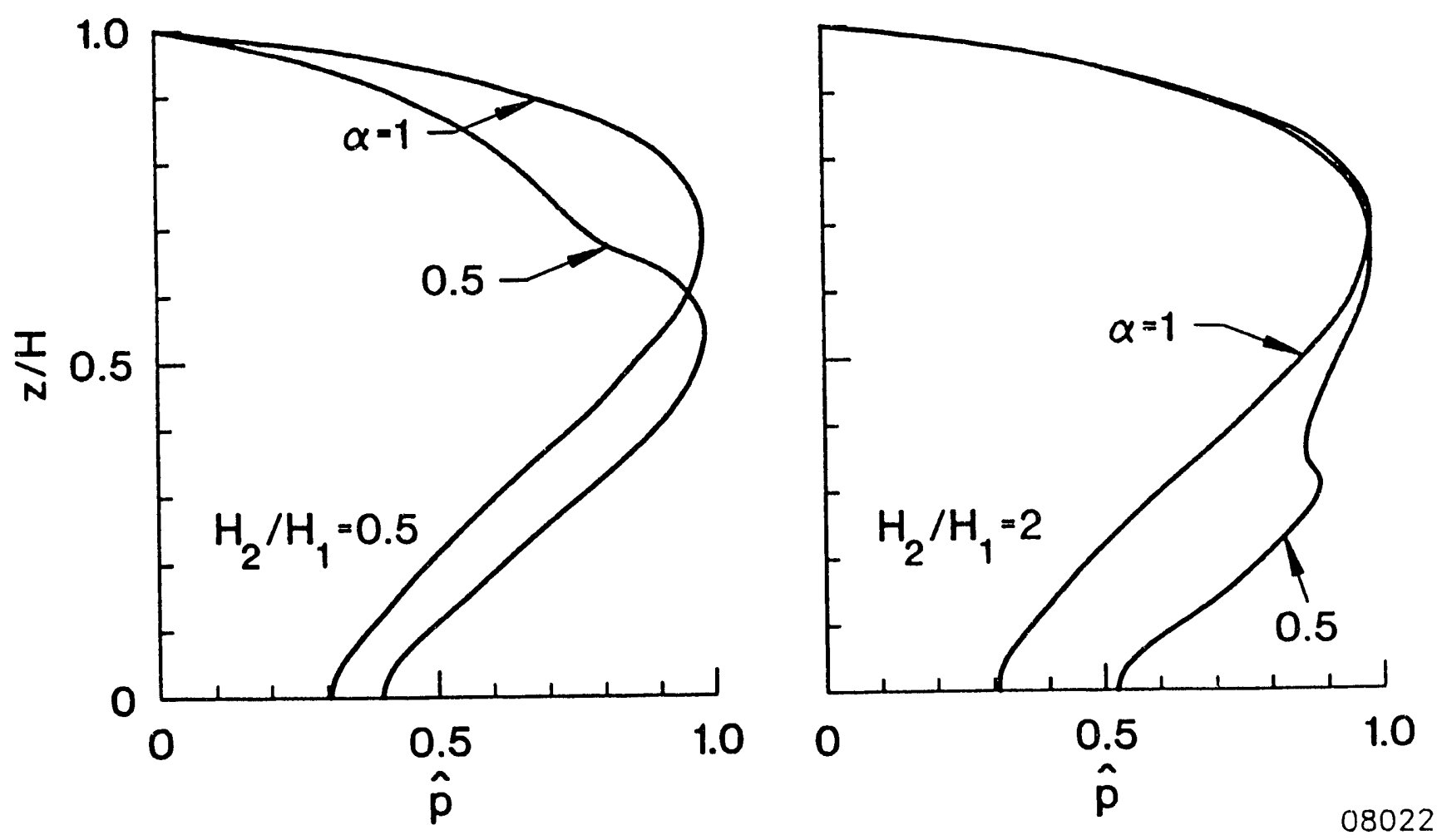

(b) $H / R=3$

Fig. 6. Distributions of Fundamental Model Hydrodynamic Pressure of Steel Tank with $h / R=0.001, \nu=0.3$ and $P_{2} / P=0.127$ 

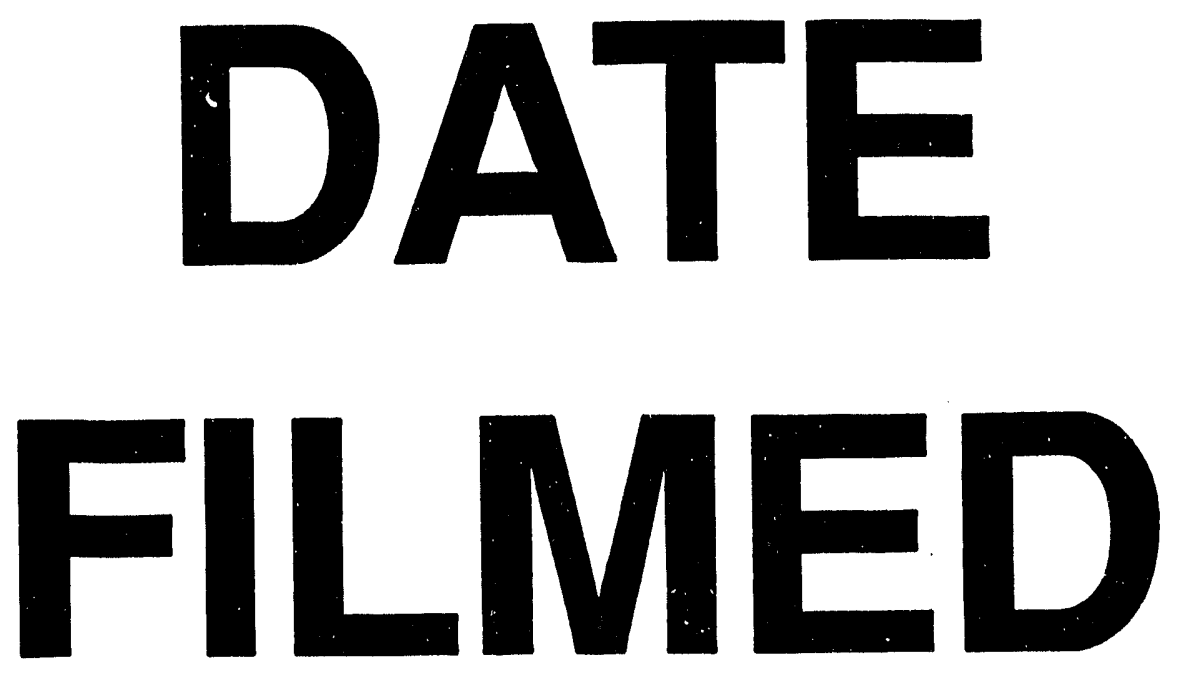

$8 / 17 / 93$
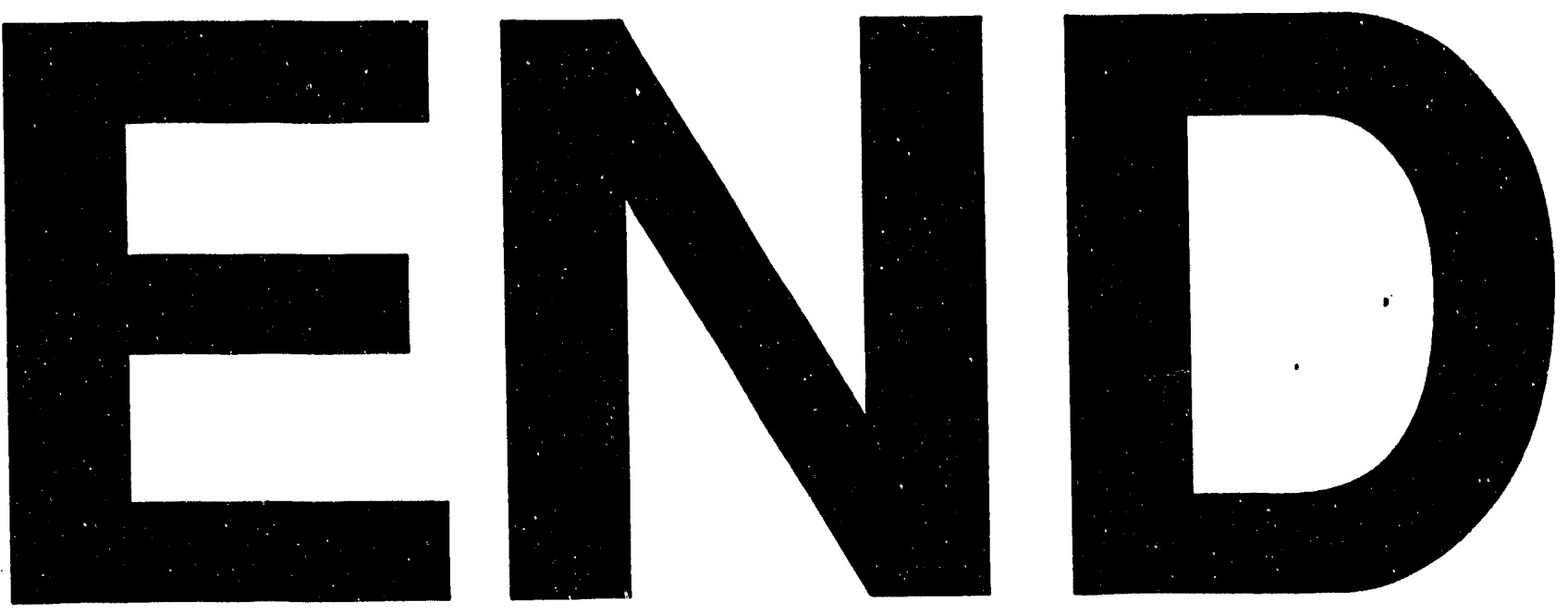


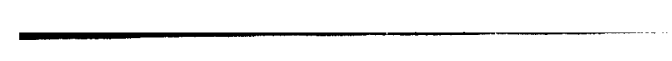

